\title{
Approach to Higher Wheat Yield in the Huang-Huai Plain: Improving Post-anthesis Productivity to Increase Harvest Index
}

\section{OPEN ACCESS}

Edited by:

Weihong Luo,

Nanjing Agricultural University, China

Reviewed by:

Mukhtar Ahmed,

Pir Mehr Ali Shah Arid Agriculture

University, Pakistan

Zhimin Wang,

China Agricultural University, China

${ }^{*}$ Correspondence:

Wei Feng

fengwei78@126.com

Yunji Zhu

hnndzyj@126.com

Specialty section:

This article was submitted to

Crop and Product Physiology,

a section of the journal

Frontiers in Plant Science

Received: 11 October 2017 Accepted: 12 September 2018

Published: 23 October 2018

Citation:

Duan J, Wu Y, Zhou Y, Ren X, Shao Y, Feng W, Zhu Y, He L and

Guo T (2018) Approach to Higher Wheat Yield in the Huang-Huai Plain: Improving Post-anthesis Productivity

to Increase Harvest Index.

Front. Plant Sci. 9:1457.

doi: 10.3389/fpls.2018.01457

\section{Jianzhao Duan' ${ }^{1}$, Yapeng Wu ${ }^{1}$, Yi Zhou' ${ }^{1}$, Xingxu Ren ${ }^{1}$, Yunhui Shao ${ }^{2}$, Wei Feng ${ }^{1 *}$, Yunji Zhu ${ }^{1 *}$, Li He ${ }^{1}$ and Tiancai Guo ${ }^{1}$}

\footnotetext{
1 State Key Laboratory of Wheat and Maize Crop Science, Collaborative Innovation Center of Henan Grain Crops, Henan Agricultural University, Zhengzhou, China, ${ }^{2}$ Wheat Research Center, Henan Academy of Agricultural Sciences, Zhengzhou, China
}

Both increased harvest index $(\mathrm{HI})$ and increased dry matter (DM) are beneficial to yield; however, little is known about the priority of each under different yield levels. This paper aims to determine whether $\mathrm{HI}$ or DM is more important and identify the physiological attributes that act as indicators of increased yield. Two field experiments involving different cultivation patterns and water-nitrogen modes, respectively, were carried out from 2013 to 2016 in Huang-Huai Plain, China. Plant DM, leaf area index (LAl), and radiation interception (RI) were measured. Increased yield under low yield levels $<7500 \mathrm{~kg} \mathrm{ha}^{-1}$ was attributed to an increase in both total DM and $\mathrm{Hl}$, while increases under higher yield levels $>7500 \mathrm{~kg} \mathrm{ha}^{-1}$ were largely dependent on an increase in $\mathrm{HI}$. Under high yield levels, $\mathrm{HI}$ showed a significant negative correlation with total DM and a parabolic relationship with net accumulation of DM during filling. Higher net accumulation of DM during filling helped slow down the decrease in $\mathrm{HI}$, thereby maintaining a high value. Moreover, net DM accumulation during filling was positively correlated with yield, while post-anthesis accumulation showed a significant linear relationship with leaf area potential (LAP, $\left.R^{2}=0.404-0.526\right)$ and radiation interception potential (RIP, $R^{2}=0.452-0.576$ ) during grain filling. These findings suggest that the increase in LAP and RIP caused an increase in net DM accumulation after anthesis. Under DM levels $>13,000 \mathrm{~kg} \mathrm{ha}^{-1}$ at anthesis, maintaining higher LAl and RI in lower layers during grain formation contributed to higher yield. Furthermore, the ratio of upper- to lower-layer RI showed a second-order curve with yield during filling, with an increase in the optimal range with grain development. Pre-anthesis translocation amount, translocation ratios and contribution ratios also showed second-order curves under high yield levels, with optimal values of $3000-4500 \mathrm{~kg} \mathrm{ha}^{-1}, 25-35$, and $30-50 \%$, respectively. These results confirm the importance of $\mathrm{HI}$ in improving the yield, thereby providing a theoretical basis for wheat production in the Huang-Huai Plain.

Keywords: winter wheat, increased yield, harvest index, dry matter, leaf area index, radiation interception 


\section{INTRODUCTION}

With the increasing world population, which is estimated to reach 9.4 billion by 2050 (Foulkes et al., 2009), global agriculture in the 21 st century is facing a significant increase in crop production. Wheat is one of the most important major food sources providing more than $20 \%$ of human calorie consumption (Merchukovnat et al., 2016). Increases in wheat yield are therefore important. Since the 1960s, it has been suggested that increases in the harvest index (HI; the proportion of total dry matter (DM) allocated to harvested grains) result in an increase in grain yield (Nass, 1980; Slafer et al., 1994; Qin et al., 2013). Thus, with the development of wheat breeding, the mean $\mathrm{HI}$ of wheat has experienced an increase from 0.35 in 1951-1955 to 0.5 in 1995-2013 (Evans and Fischer, 1999; Foulkes et al., 2009; Wiesmeier et al., 2014), while Austin (1980) predicted that the HI of modern winter wheat could reach a maximum of 0.62 . Therefore, since the HI of modern cultivars is already high, it has been suggested that further improvements in yield will rely more on increases in total DM (Aranjuelo et al., 2013; Parry and Hawkesford, 2010; Parry et al., 2010). However, in recent years, breeding of highyielding wheat has also resulted in an increase in total DM to $>18,000 \mathrm{~kg} \mathrm{ha}^{-1}$ at maturity. Some studies suggest, therefore, that further increases in wheat yield are now largely dependent on increases in $\mathrm{HI}$, rather than increases in DM (Aranjuelo et al., 2013; Fan et al., 2017). Moreover, agronomic practices such as nitrogen application and irrigation technology have further aided development, leading some to suggest that wheat yield has reached a plateau (Qin et al., 2015; Yu et al., 2017). Nevertheless, increased food production remains a priority for future world populations. In wheat production, both a high $\mathrm{HI}$ and DM are beneficial to increased yield; however, the contribution of each differs in different regions. Understanding the respective relationships between yield, DM, and $\mathrm{HI}$ in modern cultivars is therefore necessary, particularly under different yield levels, as is confirming the respective importance of DM and $\mathrm{HI}$ in terms of sustainable high yield.

Grain yield is the product of both DM and HI, with increases in yield resulting from this co-operative relationship. However, the contributions of DM and HI to yield in different regions and under different productivity levels are likely different. For a specific region, where light and temperature resources are stable and DM production potential is basically constant, increasing $\mathrm{HI}$ is a feasible approach to improving yield. However, in reality, DM production tends to reach saturation under high yield levels, and increased yield becomes more dependent on increases in HI. Research further suggests that improvements in $\mathrm{HI}$ require balance between DM production before and after anthesis (Fischer, 1981), with overproduction prior to anthesis and underproduction afterward resulting in DM accumulation in the stems and leaves rather than the grains, thereby decreasing the HI. Prior to anthesis, photosynthates are mainly stored in vegetative organs, after which they are transported to reproductive organs (Papakosta and Gagianas, 1991; Zhang et al., 2008). Previous studies suggest that saturation of preanthesis DM is important for growing spikes and the grain number per spike, resulting in a large sink (Fischer, 1985;
Slafer et al., 2014). Thus, post-anthesis photosynthetic capacity and DM mobilization from vegetative organs to grains therefore determines final grain filling. Accordingly, post-anthesis DM production and mobilization, and translocation of pre-anthesis assimilates have therefore been investigated (Fischer, 1981; Papakosta and Gagianas, 1991; Ercoli et al., 2008; Zhang et al., 2008, 2016). In general, the nutrients required for grain filling are obtained from assimilation of photosynthetic products and remobilization of stem and leaf DM. Although the degree of remobilization from vegetative organs is conducive to $\mathrm{HI}$, and therefore yield, it has limitations. The more photosynthates produced after anthesis, the more that are transported to the grains and the higher the grain yield under higher yield levels. Furthermore, while studies have examined the translocation and contribution of vegetative organ DM under different ecological regions and production conditions (Papakosta and Gagianas, 1991; Ercoli et al., 2008), little is known about the optimal translocation and contribution ratios under different yield levels. Plant DM production requires interception and absorption of light radiation for photosynthesis, with the interception of radiation thought to be correlated with the rate of photosynthesis (Richards, 2000). Thus, with wheat grain filling, green leaves gradually undergo senescence, decreasing the capacity for interception of radiation, and therefore, photosynthesis. Previous studies further suggest that a higher amount and duration of light interception during grain filling is conducive to increased photosynthesis and post-anthesis DM production (Richards, 2000; Schierenbeck et al., 2016). However, despite these findings, few studies have examined the effect of leaf area index (LAI) and intercepted radiation under different spatial altitudes on DM production under different DM levels.

In recent years, an increasing number of modern highyielding wheat cultivars have been bred and popularized. To help understand how to achieve a high $\mathrm{HI}$ and yield via an optimal canopy structure and radiation interception, we carried out a series of experiments in the Huang-Huai Plain, which accounts for approximately 55\% of the wheat planting area and $60 \%$ of wheat production in China. The aims were to: (I) describe the main factors affecting increased grain yield under different production levels ( $>$ and $<7500 \mathrm{~kg} \mathrm{ha}^{-1}$ ); (II) identify the optimal translocation and contribution ratios of pre-anthesis vegetative organ DM; (III) clarify the spatial characteristics of canopy LAI and intercepted radiation during grain filling; and (IV) characterize the physiological indicators of increased yield. The results provide a theoretical basis for further increases in grain yield in the Huang-Huai Plain.

\section{MATERIALS AND METHODS}

\section{Experimental Sites}

Two field experiments were carried out at three sites in the Huang-Huai Plain, China, from October 2013 to June 2016 Shangshui $\left(114^{\circ} 29^{\prime} \mathrm{E}, 33^{\circ} 32^{\prime} \mathrm{N}\right)$, Kaifeng $\left(114^{\circ} 37^{\prime} \mathrm{E}, 34^{\circ} 44^{\prime} \mathrm{N}\right)$, and Wenxian $\left(112^{\circ} 99^{\prime} \mathrm{E}, 34^{\circ} 92^{\prime} \mathrm{N}\right)$, in southern, central, and northern Henan Province, respectively. The climatic conditions of the study regions result in a long tillering stage (110-120 days), 
young ear differentiation period (160-170 days), and short grain filling stage (35-40 days), all of which benefit the grain number per unit area but not grain filling. Specific properties of the plow layer soil are shown in Table 1. In all three experimental sites, the preceding crop was maize, with the straw mechanically returned to the field after harvest.

With improvements in breeding and cultivation management technology, wheat yield in China has significantly improved, especially in northern wheat-growing areas, from $3000 \mathrm{~kg} \mathrm{ha}^{-1}$ in the 1950 s to $5500 \mathrm{~kg} \mathrm{ha}^{-1}$ in the $1980 \mathrm{~s}$ and to more than $7500 \mathrm{~kg}$ ha $^{-1}$ since 2010 (Wei et al., 2013; Ru et al., 2015; Wang H.G. et al., 2015). Recent high yield standards are therefore classified as $7500 \mathrm{~kg} \mathrm{ha}^{-1}$ in large areas of wheat production, with the production characteristics at a yield of $>7500 \mathrm{~kg} \mathrm{ha}^{-1}$ differing from those at $<7500 \mathrm{~kg} \mathrm{ha}^{-1}$. As a result, the approaches required to increase grain yield differ between these two yield levels. In this study, we therefore chose to use these two yield levels as the cut off between high and low yield production.

\section{Experimental Design \\ Experiment 1. Cultivation Patterns}

Four cultivation patterns were tested using the wheat cultivar Yumai 49-198: local farming practices (FP); optimized cultivation compared with FP (OFP); super high-yielding cultivation ( $\mathrm{SH}$ ); and high-yielding high-efficiency cultivation $(\mathrm{HH})$. In all cases and in all sites, the date of sowing was Oct 12-17. Under FP, rotary tillage (to about $15 \mathrm{~cm}$ ) was carried out before sowing with no rolling after seeding. Irrigation was carried out after sowing and during the returning green stage. Equal row spacing of $20 \mathrm{~cm}$ and a large sowing quantity $(225 \mathrm{~kg}$ $\mathrm{ha}^{-1}$ ) were applied. Under OFP, $\mathrm{SH}$, and $\mathrm{HH}$, mechanical deep plowing (more than $25 \mathrm{~cm}$ ) was adopted, with multiple rotary harrowing and rolling after seeding. Irrigation was carried out after sowing and during jointing. Equal row spacing of $20 \mathrm{~cm}$ was adopted in OFP, and $17 \mathrm{~cm}$ in $\mathrm{SH}$ and $\mathrm{HH}$. A sowing quantity of $150 \mathrm{~kg} \mathrm{ha}^{-1}$ was applied in OFP, and $120 \mathrm{~kg} \mathrm{ha}^{-1}$ in both $\mathrm{SH}$ and $\mathrm{HH}$. Irrigation was carried out, and organic, microelement, and phosphate and potassium fertilizers were applied before sowing (Table 2). Under FP, all N (urea), phosphate $\left(\mathrm{P}: \mathrm{P}_{2} \mathrm{O}_{5}\right)$, and potassium $\left(\mathrm{K}: \mathrm{K}_{2} \mathrm{O}\right)$ fertilizers were applied as base fertilizer before sowing. Under OFP and $\mathrm{SH}, 50 \%$ of the $\mathrm{N}$ fertilizer and all $\mathrm{P}$ and $\mathrm{K}$ fertilizers were applied before sowing, with the remaining $50 \% \mathrm{~N}$ fertilizer applied at jointing. Under $\mathrm{HH}, 40 \%$ of the $\mathrm{N}$ fertilizer and $70 \%$ of the $\mathrm{P}$ and $\mathrm{K}$ fertilizers were applied before sowing, with the remaining 60 and 30\%, respectively, applied at jointing. All organic $\left(1.63 \% \mathrm{~N}, 1.54 \% \mathrm{P}_{2} \mathrm{O}_{5}\right.$, and $\left.0.85 \% \mathrm{~K}_{2} \mathrm{O}\right)$ and microelement fertilizers $\left(\mathrm{ZnSO}_{4}\right)$ were applied before sowing. Details of the fertilizer and irrigation regimes are shown in Table 2.

The four cultivation patterns therefore involved individual characteristics. Specifically, FP treatment involved a larger seeding rate, single basal application of fertilizers before sowing, and irrigation during the returning green stage. OFP treatment focused on a reduced fertilizer application rate, with proper topdressing and irrigation at jointing compared to FP. SH treatment was carried out to achieve the highest possible yield regardless of the cost of fertilization and irrigation, while $\mathrm{HH}$ treatment was focused on achieving high yield and high efficiency by reducing the fertilizer application rate and optimizing nitrogen application

TABLE 1 | Basic physicochemical properties of the field experiment sites at a soil depth of 0-40 $\mathrm{cm}$.

\begin{tabular}{|c|c|c|c|c|c|c|c|c|c|}
\hline Items* & \multicolumn{3}{|c|}{ Shangshui } & \multicolumn{3}{|c|}{ Kaifeng } & \multicolumn{3}{|c|}{ Wenxian } \\
\hline TN & 0.95 & 1.25 & 1.33 & 0.80 & 0.96 & 1.01 & 0.89 & 0.93 & 0.95 \\
\hline AEN & 90.35 & 110.00 & 118.33 & 74.70 & 85.43 & 99.25 & 93.90 & 100.54 & 102.95 \\
\hline $\mathrm{OM}$ & 16.68 & 18.47 & 18.78 & 12.96 & 14.86 & 15.12 & 12.57 & 13.93 & 14.02 \\
\hline Texture & LCBS & LCBS & LCBS & Clay & Clay & Clay & FACS & FACS & FACS \\
\hline
\end{tabular}

*TN, total $N\left(g \mathrm{~kg}^{-1}\right)$; $A E N$, alkaline extractable $N\left(\mathrm{mg} \mathrm{kg}^{-1}\right)$; OM, organic matter $(\mathrm{g} \mathrm{kg}-1)$; APP, available phosphorus $\left(\mathrm{mg} \mathrm{kg}^{-1}\right)$; $A P S$, available potassium $\left(\mathrm{mg} \mathrm{kg}^{-1}\right)$; LCBS, lime concretion black soil; FACS, fluvo-aquic clay soil.

TABLE 2 | Irrigation and fertilization management under each cultivation pattern in the field experiments.

\begin{tabular}{|c|c|c|c|c|c|c|c|c|c|}
\hline \multirow{2}{*}{$\begin{array}{l}\text { Treatment } \\
*\end{array}$} & \multicolumn{5}{|c|}{ Rate of fertilizer application $\left(\mathrm{kg} \mathrm{ha}^{-1}\right)$} & \multicolumn{4}{|c|}{ Irrigation amount at each stage $\left(\mathrm{m}^{3} \mathrm{ha}^{-1}\right)$} \\
\hline & $\mathbf{N}$ & $\mathrm{P}_{2} \mathrm{O}_{5}$ & $\mathrm{~K}_{2} \mathrm{O}$ & $\mathrm{ZnSO}_{4}$ & Organic fertilizer & Soil moisture water & Turning green stage & Jointing stage & Blossom filling stage \\
\hline FP & 225 & 75 & 60 & 0 & 0 & 900 & 600 & 0 & 900 \\
\hline OFP & 180 & 75 & 60 & 0 & 0 & 600 & 0 & 900 & 750 \\
\hline $\mathrm{SH}$ & 300 & 150 & 150 & 15 & 1500 & 600 & 0 & 900 & 900 \\
\hline $\mathrm{HH}$ & 240 & 90 & 90 & 15 & 1500 & 600 & 0 & 900 & 750 \\
\hline
\end{tabular}

*FP, local farming practice; OFP, optimized cultivation compared with FP; SH, super high-yielding cultivation; HH, high-yielding and high-efficiency cultivation. 
(i.e., top dressing) and irrigation compared to $\mathrm{SH}$. This treatment followed a randomized block design with three replications. Each plot was $165 \mathrm{~m}^{2}$ (15 $\mathrm{m}$ in length and $11 \mathrm{~m}$ wide).

\section{Experiment 2. Water-Nitrogen Modes}

Water-nitrogen mode experiments were carried out using the wheat cultivar Aikang 58, sown on Oct 12-17 in Shangshui and Wenxian. In Shangshui, the experiments consisted of a combination of two irrigation regimes (no irrigation and single irrigation of $750 \mathrm{~m}^{3} \mathrm{ha}^{-1}$ at jointing) and four $\mathrm{N}$ rates $(0,180,240$, and $300 \mathrm{~N} \mathrm{~kg} \mathrm{ha}^{-1}$ ). In Wenxian, the experiments consisted of three irrigation regimes (no irrigation, single irrigation of $750 \mathrm{~m}^{3}$ $\mathrm{ha}^{-1}$ at jointing, and irrigation of $750 \mathrm{~m}^{3} \mathrm{ha}^{-1}$ at jointing plus anthesis) and four $\mathrm{N}$ rates (as listed above). As a base fertilizer, $50 \% \mathrm{~N}$ fertilizer (Wenxian) or 70\% N fertilizer (Shangshui) was applied along with all $\mathrm{P}\left(100 \mathrm{~kg} \mathrm{P} \mathrm{ha}^{-1}\right)$ and $\mathrm{K}\left(150 \mathrm{~kg} \mathrm{~K} \mathrm{ha}^{-1}\right)$ fertilizers before sowing. The remaining $\mathrm{N}$ fertilizer was applied at jointing. Experimental plots were arranged in a split-plot design with three replicates, with each plot measuring $40.6 \mathrm{~m}^{2}$ (7 $\mathrm{m}$ in length and $5.8 \mathrm{~m}$ wide). The main plot was assigned to the irrigation regime and the subplot to the $\mathrm{N}$ rate.

\section{Growing Season Conditions and Crop Phenology}

The experimental sites have a warm temperate, semi-humid, continental monsoon climate. Detailed climatic conditions of each site in each year are shown in Figure 1. In general, the total rainfall, effective accumulated temperature $\left(>0^{\circ} \mathrm{C}\right)$, and photosynthetic active radiation were higher in Shangshui than in Kaifeng and Wenxian, while photosynthetic active radiation was higher in Kaifeng than in Wenxian. From 2013 to 2016, the total ranges in effective accumulated temperature $\left(>0^{\circ} \mathrm{C}\right)$ and photosynthetic active radiation varied little in Shangshui. However, in all the three sites, rainfall varied between 2015 and 2016, and was higher than in previous years, thereby having an advantageous effect on wheat growth.

\section{Sampling and Measurements Biomass}

Timing of each developmental stage from anthesis to maturity was determined as the point when $50 \%$ of plants reached a specific standard. Aboveground DM was measured at different growth stages (anthesis, early grain filling, mid-grain filling, and maturity). Twenty plants were randomly sampled three times from anthesis to maturity, resulting in a total of 60 plants and covering an area approximating $0.2 \mathrm{~m}^{2}$. They were divided into stems, leaves, and spikes, oven dried at $65^{\circ} \mathrm{C}$, and then used to determine DM. Net DM accumulation during filling was calculated as the difference between the total DM at anthesis and maturity.

\section{Leaf area index (LAI) and radiation interception (RI)}

Green leaf area can be represented by the LAI, which is further divided according to spatial architecture into upper- and lowerlayer LAI. The total LAI (LAIt) was determined at the base of the plants using a plant canopy analyzer (LAI 2200C, LI-COR, Lincoln, NE, United States), while the upper-layer LAI (LAIu) was determined at the third leaf from the top of the flag. Lowerlayer LAI (LAIL) was then calculated by the difference between LAIu and LAIt. Sampling was carried out at anthesis, early grain filling (7 days after anthesis), mid-grain filling (15 days after anthesis), and 21 days after anthesis.

The ability to intercept radiation was estimated by measuring the photosynthetic active radiation (PAR) from 11:00 to 13:00 on a sunny day under the canopy $\left(\mathrm{MJ} \mathrm{m}^{-2}\right)$ using a $1 \mathrm{~m}$ long linear sensor (LI 191S, LI-COR Inc., Lincoln, NE, United States). Incident PAR (Io) and reflected PAR (R) were measured at the top of the canopy, and mid and base incident PAR were measured at the same positions as used to determine LAI, i.e., the third leaf from the top of the flag $\left(\mathrm{I}_{\mathrm{m}}\right)$ and the base plant $\left(\mathrm{I}_{\mathrm{b}}\right)$. The ratio of upper- to lower-layer radiation interception (f) was then calculated as follows:

$$
\mathrm{f}=\left(\mathrm{I}_{0}-\mathrm{I}_{\mathrm{m}}-\mathrm{R}\right) /\left(\mathrm{I}_{\mathrm{m}}-\mathrm{I}_{\mathrm{b}}\right)
$$

and the radiation interception rate $(\mathrm{F})$ defined as the ratio of total radiation interception to incident PAR $\left(\mathrm{I}_{\mathrm{o}}\right)$ was calculated as follows:

$$
\mathrm{F}=\left(\mathrm{I}_{0}-\mathrm{I}_{\mathrm{b}}-\mathrm{R}\right) / \mathrm{I}_{0}
$$

The accumulation of leaf area and RI with time (days) has a significant effect on wheat production; therefore, the average leaf area potential (LAP) and radiation interception potential (RIP) were calculated as follows:

$$
\mathrm{LAP}=1 / 2\left(\mathrm{LAI}_{\mathrm{t} 1}+\mathrm{LAI}_{\mathrm{t} 2}\right)^{*} \mathrm{~T}
$$

where $\mathrm{LAI}_{\mathrm{t} 1}$ and $\mathrm{LAI}_{\mathrm{t} 2}$ represent two adjacent $\mathrm{LAI}$ values, and $\mathrm{T}$ is the number of days between measurements.

$$
\mathrm{RIP}=1 / 2(\mathrm{~F} 1+\mathrm{F} 2)^{*} \mathrm{~T}
$$

where $\mathrm{F} 1$ and $\mathrm{F} 2$ represent two adjacent radiation interception rate $(\mathrm{F})$ values, and $\mathrm{T}$ is the number of days between measurements.

\section{Grain yield and $\mathrm{HI}$}

At maturity, an area of $5 \mathrm{~m}^{2}$ was harvested, and the harvested samples were threshed and dried to determine the grain yield $\left(\mathrm{kg} \mathrm{ha}^{-1}\right)$. HI was determined as the ratio of grain yield to total DM at maturity.

\section{Statistical Analysis}

Yield, DM and HI data were obtained from the cultivation and water-nitrogen mode experiments carried out from 2013 to 2016 (total: 288 samples). LAI and light radiation data were obtained from the cultivation experiments carried out in Shangshui and Kaifeng from 2014 to 2016 and the water-nitrogen mode experiments carried out in Shangshui and Wenxian from 2014 to 2016 (total: 168 samples). Experimental data were analyzed and processed using Microsoft Office 2013. Variance analysis was carried out using Duncan's multiple range test at a significance level of 5\% and Pearson's correlation analysis at $P<0.05$ using SPSS version 19.0. 


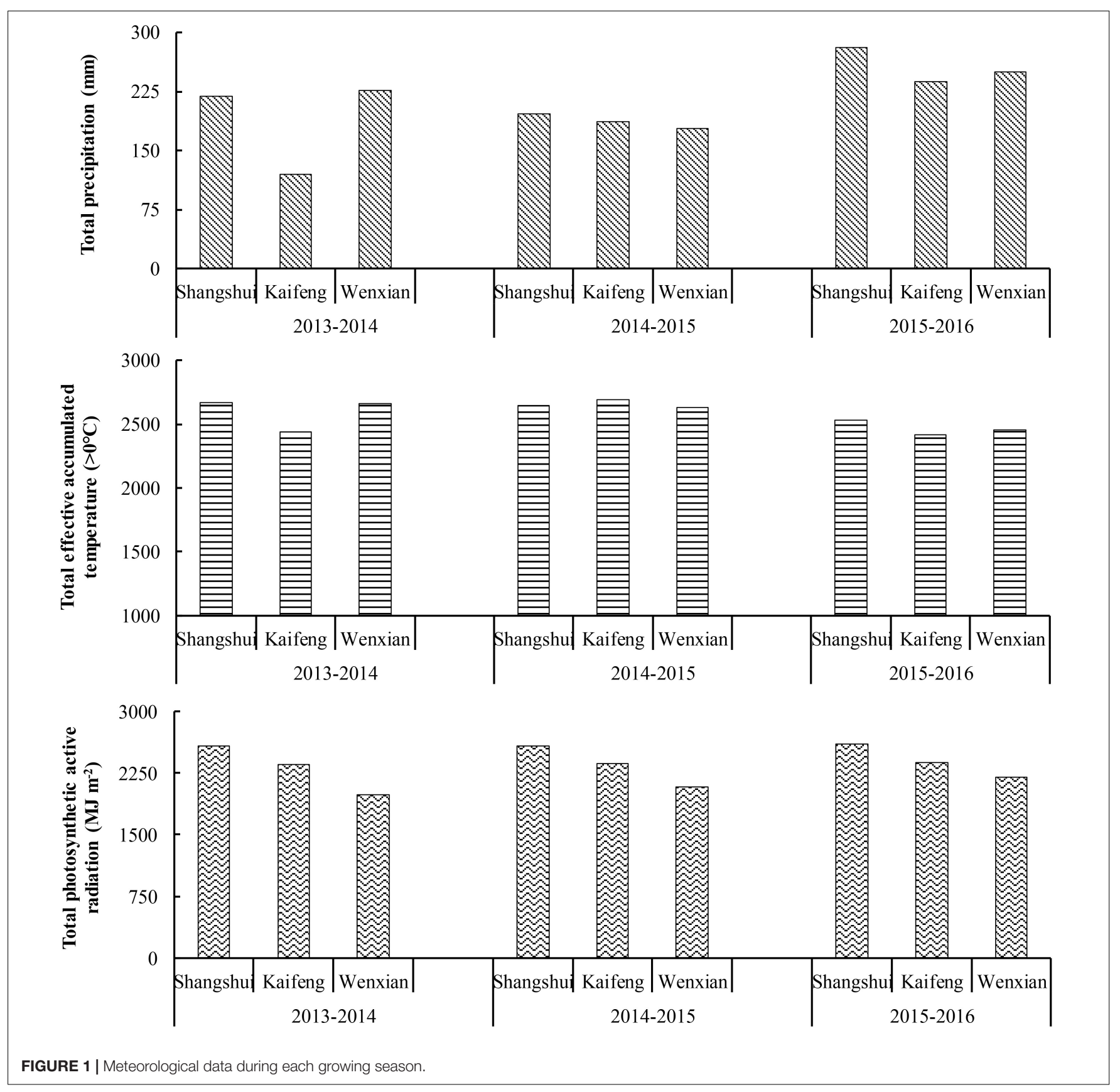

\section{RESULTS}

\section{Relationships Between Yield, DM and HI}

As shown in Table 3, the cultivation pattern experiments involving Yumai 49-198 showed that $\mathrm{SH}$ and $\mathrm{HH}$ resulted in higher yield, GN (grain number per unit area), HI, and DM than FP treatment in all the three locations (Table 4). Yield, GN, and DM showed the same trend between locations: Shangshui $>$ Wenxian $>$ Kaifeng, while the thousand grain weight (TGW), HI, and total DM revealed variations. Meanwhile, the water-nitrogen mode experiments using Aikang 58 had a significant effect on yield, the yield components, HI, and DM in Shangshui and Wenxian (Table 5). Yield, GN, HI, and DM increased with increasing $\mathrm{N}$ application rate from 0 to $240 \mathrm{~kg}$ $\mathrm{ha}^{-1}$ and increasing irrigation application from 0 to 2 times. Under high $\mathrm{N}$ application rates, the above indicators showed no significant differences between N240 and N300, decreasing under W2. Overall, therefore, irrigation, nitrogen, and cultivation management strongly affected yield and other physiological indicators.

In this study, yield showed a similar relationship with GN, DM, and HI in both cultivars (Yumai 49-198 and Aikang 58), and the experimental data from both experiments in the three locations was therefore pooled for analysis. Figures 2A,B and 
TABLE 3 | Descriptive statistics of yield, yield components, HI, and DM accumulation.

\begin{tabular}{|c|c|c|c|c|c|}
\hline Component* & $N$ & Average & Maximum & Minimum & $S D$ \\
\hline Yield & 288 & 7222.84 & 10194.67 & 2980.08 & 1715.46 \\
\hline GN & 288 & 18.96 & 32.17 & 6.18 & 5.57 \\
\hline TGW & 288 & 46.64 & 54.98 & 37.84 & 3.58 \\
\hline $\mathrm{HI}$ & 288 & 0.42 & 0.53 & 0.27 & 0.05 \\
\hline $\mathrm{DM}_{\mathrm{A}}$ & 288 & 12733.74 & 18268.22 & 5884.80 & 2796.04 \\
\hline $\mathrm{DM}_{\mathrm{M}}$ & 288 & 17280.67 & 23384.75 & 9038.83 & 3502.11 \\
\hline $\mathrm{DM}_{\mathrm{AM}}$ & 288 & 4480.50 & 6877.28 & 2222.52 & 1096.22 \\
\hline TDM & 288 & 2675.90 & 5185.75 & 185.79 & 1148.60 \\
\hline
\end{tabular}

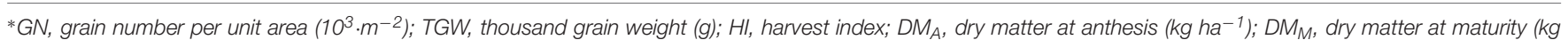
$\left.\mathrm{ha}^{-1}\right) ; D M_{A M}$, dry matter accumulation from anthesis to maturity $\left(\mathrm{kg} \mathrm{ha}^{-1}\right)$; TDM, dry matter translocation amount after anthesis $\left(\mathrm{kg}^{2} \mathrm{a}^{-1}\right)$.

TABLE 4 | ANOVA of grain yield, yield components, HI, and DM accumulation under each cultivation pattern experiment (cultivar Yumai 49-198).

\begin{tabular}{|c|c|c|c|c|c|c|c|c|c|}
\hline Locations & Treatments & Yield & GN & TGW & $\mathrm{HI}$ & $\mathrm{DM}_{\mathrm{A}}$ & $\mathrm{DM}_{\mathrm{M}}$ & $\mathrm{DM}_{\mathrm{AM}}$ & TDM \\
\hline Shangshu & $\mathrm{FP}$ & $7298.27 b$ & 18.86b & $48.73 a$ & $0.40 b$ & $13542.50 \mathrm{~b}$ & $18281.85 b$ & $4550.48 b$ & 2558.93b \\
\hline \multirow[t]{3}{*}{ i } & $\mathrm{JH}$ & $8007.41 b$ & $21.99 \mathrm{ab}$ & 45.90ab & $0.44 a$ & 13944.50ab & 18523.34b & $4578.85 b$ & $3428.57 a$ \\
\hline & $\mathrm{SH}$ & $9313.61 a$ & $25.52 a$ & 44.98b & $0.44 a$ & $15364.96 a$ & $21392.65 a$ & $6027.78 a$ & $3285.91 \mathrm{ab}$ \\
\hline & $\mathrm{HH}$ & $9081.40 a$ & $25.17 a$ & $45.25 b$ & $0.43 a b$ & $15572.77 a$ & $21295.46 a$ & $5744.93 a$ & $3358.71 \mathrm{ab}$ \\
\hline \multirow[t]{4}{*}{ Kaifeng } & FP & $6922.99 b$ & $18.34 b$ & $46.13 a$ & $0.42 b$ & 11998.81b & $16439.48 b$ & $4440.68 b$ & 2482.32b \\
\hline & $\mathrm{JH}$ & $7523.00 b$ & $20.63 a b$ & $46.84 a$ & $0.42 b$ & 13983.95ab & 18297.46ab & $4424.69 b$ & $3209.49 a b$ \\
\hline & $\mathrm{SH}$ & $8819.50 a$ & $23.23 a$ & $45.46 a$ & $0.46 a$ & $14425.34 a$ & $19253.04 a$ & 5016.59ab & 3991.81a \\
\hline & $\mathrm{HH}$ & $8644.10 a$ & $23.83 a$ & $43.77 a$ & $0.44 a b$ & $14275.03 \mathrm{ab}$ & $19763.25 a$ & $5510.42 a$ & $3155.88 \mathrm{ab}$ \\
\hline \multirow[t]{4}{*}{ Wenxian } & $\mathrm{FP}$ & $7139.25 c$ & $18.25 b$ & $47.46 a$ & $0.42 b$ & 12727.80b & 17168.56b & $4140.72 b$ & $2698.48 b$ \\
\hline & $\mathrm{JH}$ & $7830.30 b$ & $21.35 a$ & $48.18 a$ & $0.42 b$ & $14178.54 a b$ & 18517.02ab & 4338.48ab & $3491.82 a$ \\
\hline & $\mathrm{SH}$ & $9081.49 a$ & $24.13 a$ & $45.74 a$ & $0.46 a$ & $14664.02 \mathrm{a}$ & 19797.38a & 4955.62ab & $3948.13 a$ \\
\hline & $\mathrm{HH}$ & $8762.29 a$ & $23.87 a$ & $45.79 a$ & $0.45 a$ & $14454.75 a b$ & $19545.89 a$ & $5091.15 a$ & $3671.15 a$ \\
\hline
\end{tabular}

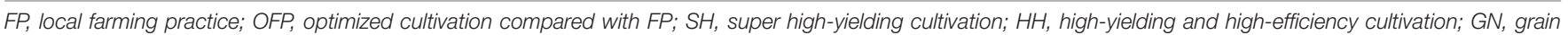

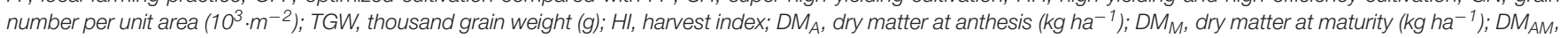
dry matter accumulation from anthesis to maturity $\left(\mathrm{kg} \mathrm{ha}^{-1}\right)$; TDM, dry matter translocation amount after anthesis $\left(\mathrm{kg} \mathrm{ha}^{-1}\right)$.

Table 6 show the relationship between yield and aboveground DM (biomass), yield components, and HI. These relationships showed larger differences at the yield threshold of $7500 \mathrm{~kg} \mathrm{ha}^{-1}$, $7500 \mathrm{~kg} \mathrm{ha}^{-1}$ acting as the dividing line for analysis of the contribution of DM to yield. Here, a yield of $<7500 \mathrm{~kg} \mathrm{ha}^{-1}$ was defined as a low yield level, while $>7500 \mathrm{~kg} \mathrm{ha}^{-1}$ was a high yield level. Under low yield levels, significant positive linear relationships were observed between yield and total DM at both anthesis $\left(R^{2}=0.506, P<0.001\right)$ and maturity $\left(R^{2}=0.691\right.$, $P<0.001)$. Meanwhile, under high yield levels, poor correlations were observed at both stages $(P>0.05)$. Yield was significantly related to $\mathrm{HI}$ at both yield levels (Figure 2C; $R^{2}=0.356, P<0.001$ and $R^{2}=0.538, P<0.001$ for $>7500 \mathrm{~kg} \mathrm{ha}^{-1}$ and $<7500 \mathrm{~kg}$ $\mathrm{ha}^{-1}$, respectively). These findings suggest that improvements in yield under low yield levels are attributable to increases in both DM and HI, while increases under high yield levels are mainly dependent on marked increases in HI. Furthermore, the total DM under high yield levels tended to be higher than under low yield levels. Moreover, as the total DM continued to increase, yield tended to reach saturation, suggesting that further improvements in yield are dependent on HI.

As shown in Table 6, yield and HI showed a significant positive correlation with GN and a negative correlation with TGW, both at high and low yield levels. These findings suggest that high GN is conducive to high yield. In addition, yield components determine the sink size and affect the HI. The above results suggest that increasing GN contributes to a high HI.

\section{Effect of Total DM and Net DM Accumulation on $\mathrm{HI}$ and Yield}

$\mathrm{HI}$ exhibited a parabolic trend with total DM at both anthesis and maturity when experimental data were pooled (Figures 3A,B). However, the relationship between $\mathrm{HI}$ and total DM differed according to yield level. A positive correlation was observed between $\mathrm{HI}$ and total $\mathrm{DM}$ at anthesis and maturity under low yield levels $\left(R^{2}=0.165-0.271, P<0.001\right)$, while, in contrast, a significant negative correlation was observed at anthesis $\left(R^{2}=0.381, P<0.001\right)$ and maturity $\left(R^{2}=0.486\right.$, $P<0.001)$ under high yield levels. Moreover, as shown in Figures 2A,B, 3A,B, DM of 13,000 kg ha-1 at anthesis and $18,000 \mathrm{~kg} \mathrm{ha}^{-1}$ at maturity were required to determine the dynamic relationships between yield, HI, and DM. In particular, DM accumulation during filling plays an important role in grain filling. When data were pooled, HI showed a parabolic relationship with DM accumulation from anthesis to maturity (Figure 3C). Meanwhile, under low yield levels, HI showed 
TABLE 5 | ANOVA of grain yield, yield components, HI, and DM accumulation under each water-nitrogen mode experiment (cultivar Aikang 58).

\begin{tabular}{|c|c|c|c|c|c|c|c|c|c|}
\hline Location & Treatment* & Yield & GN & TGW & HI & $\mathrm{DM}_{\mathrm{A}}$ & $\mathrm{DM}_{\mathrm{M}}$ & $\mathrm{DM}_{\mathrm{AM}}$ & TDM \\
\hline \multirow[t]{8}{*}{ Shangshui } & WONO & $3956.77 e$ & $9.49 d$ & 48.23ab & $0.34 b$ & $8616.36 c$ & $11684.75 d$ & 3068.39d & $888.38 \mathrm{e}$ \\
\hline & WON180 & $5733.47 c$ & $14.51 \mathrm{bc}$ & $46.52 \mathrm{ab}$ & $0.43 a$ & 9853.93bc & $13425.55 \mathrm{~cd}$ & $3671.58 \mathrm{~cd}$ & $2161.84 \mathrm{~cd}$ \\
\hline & WON240 & 5890.90c & $14.29 \mathrm{bc}$ & 46.71ab & $0.40 a$ & 10825.34b & $14651.13 c$ & $3792.50 \mathrm{bcd}$ & 2065.11cd \\
\hline & WON300 & $6453.04 c$ & $15.69 b$ & 49.01a & $0.43 a$ & $11156.87 b$ & 15238.30c & 4081.43bc & $2371.61 \mathrm{bc}$ \\
\hline & W1NO & $4954.68 d$ & $12.67 \mathrm{c}$ & $49.84 a$ & $0.39 a$ & $9117.81 \mathrm{c}$ & $12638.72 d$ & $3520.90 \mathrm{~cd}$ & 1433.77de \\
\hline & W1N180 & $7283.04 b$ & $19.57 a$ & $47.23 a b$ & $0.41 a$ & $13146.15 a$ & $17727.23 b$ & $4100.26 b c$ & 2701.97abc \\
\hline & W1N240 & $8076.29 a$ & $21.66 \mathrm{a}$ & $44.86 b$ & $0.43 a$ & $14202.48 a$ & 18908.55ab & 4556.94ab & $3370.22 \mathrm{a}$ \\
\hline & W1N300 & $8126.02 a$ & $20.98 a$ & 46.40ab & $0.42 a$ & $14520.23 a$ & $19607.21 a$ & $5031.49 a$ & $3039.05 a b$ \\
\hline \multirow[t]{12}{*}{ Wenxian } & WONO & $3758.05 e$ & $8.19 d$ & $50.92 a$ & $0.34 b$ & $8178.96 e$ & $11172.37 e$ & $2993.41 \mathrm{~g}$ & $764.6 d$ \\
\hline & WON180 & $6506.46 \mathrm{bc}$ & $15.75 b$ & $45.58 c$ & $0.42 a$ & $10686.75 \mathrm{~cd}$ & $15345.41 b c$ & 4658.66bcd & $1847.80 c$ \\
\hline & WON240 & $6233.01 c$ & $16.77 \mathrm{~b}$ & $46.81 b c$ & $0.42 a$ & $10841.07 \mathrm{~cd}$ & $15058.80 \mathrm{bc}$ & 4217.73cde & $2015.28 b c$ \\
\hline & WON300 & $6541.63 \mathrm{bc}$ & 17.33b & $46.11 \mathrm{bc}$ & $0.43 a$ & $11482.79 \mathrm{~cd}$ & $15246.02 b c$ & 3871.63def & $2778.40 \mathrm{ab}$ \\
\hline & W1N0 & 4493.83de & $11.20 \mathrm{~cd}$ & 49.61ab & $0.35 b$ & 9841.63de & 12896.00de & $3087.72 \mathrm{fg}$ & $1439.46 \mathrm{~cd}$ \\
\hline & W1N180 & $7311.11 b$ & $21.20 \mathrm{a}$ & $44.51 \mathrm{c}$ & $0.43 a$ & $12499.05 b c$ & 17072.83b & 4573.78bcde & 2737.33ab \\
\hline & W1N240 & $8456.60 a$ & $20.87 a$ & $45.83 c$ & $0.42 a$ & $14586.38 a$ & $20255.81 a$ & 5024.96abc & $2787.16 \mathrm{ab}$ \\
\hline & W1N300 & $8319.03 a$ & $20.81 a$ & $46.51 \mathrm{bc}$ & $0.42 a$ & $14748.87 a$ & 19809.18a & 4714.66bcd & $3258.72 a$ \\
\hline & W2N0 & $5222.99 d$ & $13.92 \mathrm{bc}$ & $47.87 \mathrm{abc}$ & $0.38 a b$ & 9996.08de & $13744.44 \mathrm{~cd}$ & 3748.36efg & $1474.63 \mathrm{~cd}$ \\
\hline & W2N180 & $8247.55 a$ & $20.58 \mathrm{a}$ & $45.23 c$ & $0.43 a$ & 14249.06ab & $19451.20 a$ & 4913.26abc & $3045.41 a$ \\
\hline & W2N240 & 8653.38a & $22.74 a$ & $46.12 \mathrm{bc}$ & $0.42 a$ & $15121.30 \mathrm{a}$ & $20456.89 a$ & 5291.18ab & $3317.79 a$ \\
\hline & W2N300 & $8489.27 a$ & $23.37 a$ & $44.48 c$ & $0.42 a$ & $14675.56 a$ & $20315.70 a$ & $5636.83 a$ & $2849.12 a b$ \\
\hline
\end{tabular}

* Experimental treatments consisted of: no irrigation under four $\mathrm{N}$ rates $(0,180,240$, and $300 \mathrm{~N} \mathrm{~kg} \mathrm{ha-1;} \mathrm{WONO,} \mathrm{WON180,} \mathrm{WON240,} \mathrm{and} \mathrm{WON300);} \mathrm{single} \mathrm{irrigation} \mathrm{at}$ jointing under four N rates (W1NO, W1N180, W1N240, and W1N300); and irrigation at jointing plus anthesis under four N rates (W2NO, W2N180, W2N240, and W2N300). GN, grain number per unit area $\left(10^{3} \cdot \mathrm{m}^{-2}\right)$; TGW, thousand grain weight (g); HI, harvest index; DMA, dry matter at anthesis $\left(\mathrm{kg} h \mathrm{~h}^{-1}\right) ; \mathrm{DM}_{\mathrm{M}}$, dry matter at maturity $(\mathrm{kg}$ $\left.\mathrm{ha}^{-1}\right) ; D M_{A M}$, dry matter accumulation from anthesis to maturity $\left(\mathrm{kg} \mathrm{ha}^{-1}\right)$; TDM, dry matter translocation amount after anthesis $\left(\mathrm{kg} \mathrm{ha}^{-1}\right)$.

A

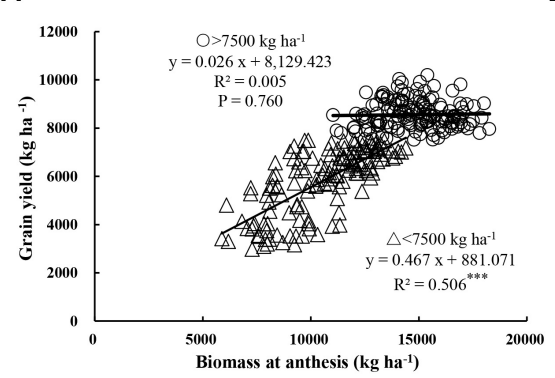

B

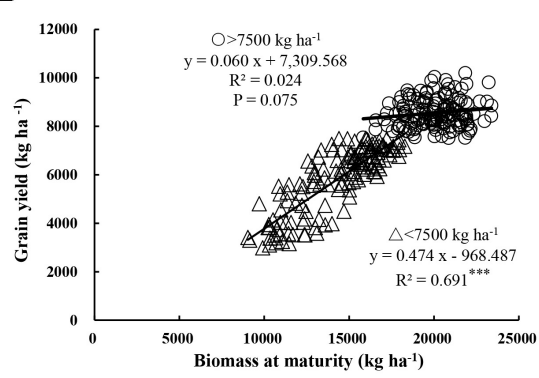

c

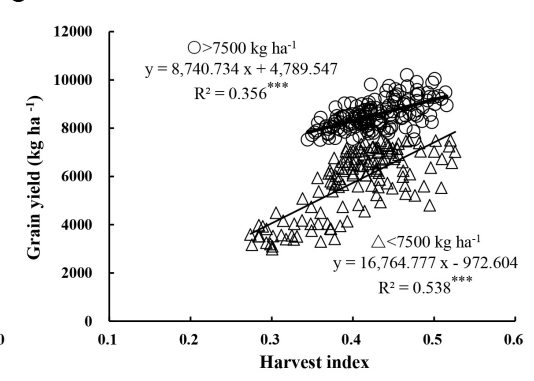

FIGURE 2 | Relationships between grain yield and biomass at anthesis (A) and maturity (B), and harvest index (C), respectively. Significant at ${ }^{*} p=0.05,{ }^{* *} p=0.01$, and ${ }^{* * *} p=0.001$.

TABLE 6 | Pearson's correlation between yield and yield components, HI, and DM accumulation $(n=288)$.

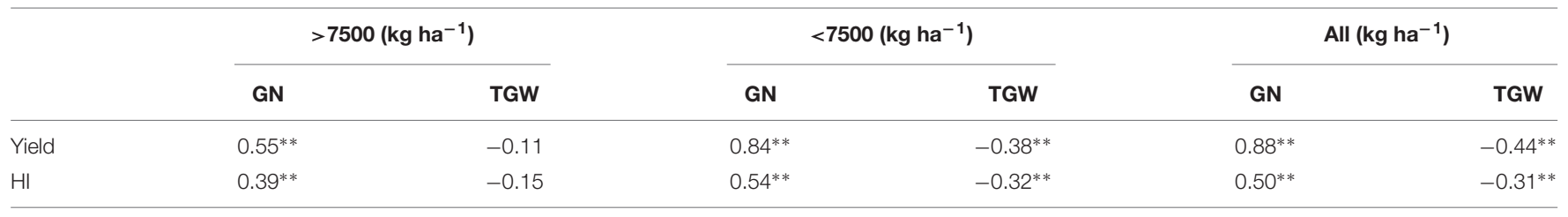

** Significant at 0.01 probability. GN, grain number per unit area $\left(10^{3} \cdot \mathrm{m}^{-2}\right) ; \mathrm{TGW}$, thousand grain weight (g); HI, harvest index; DMA, dry matter at anthesis $\left(\mathrm{kg}\right.$ ha $\left.{ }^{-1}\right)$; $D M_{M}$, dry matter at maturity $\left(\mathrm{kg} \mathrm{ha}^{-1}\right) ; D M_{A M}$, dry matter accumulation from anthesis to maturity $\left(\mathrm{kg} \mathrm{ha}^{-1}\right)$.

a positive correlation $\left(R^{2}=0.351, P<0.001\right)$ with net accumulation of DM during grain filling. These findings suggest that under low yield levels, the net accumulation of DM during filling had a stronger significant effect on $\mathrm{HI}$ than total DM at both anthesis and maturity. In contrast, under high yield levels, HI showed a parabolic relationship with net accumulation of DM during grain filling. In other words, excessive total DM caused a decrease in $\mathrm{HI}$, while high net accumulation during grain filling 

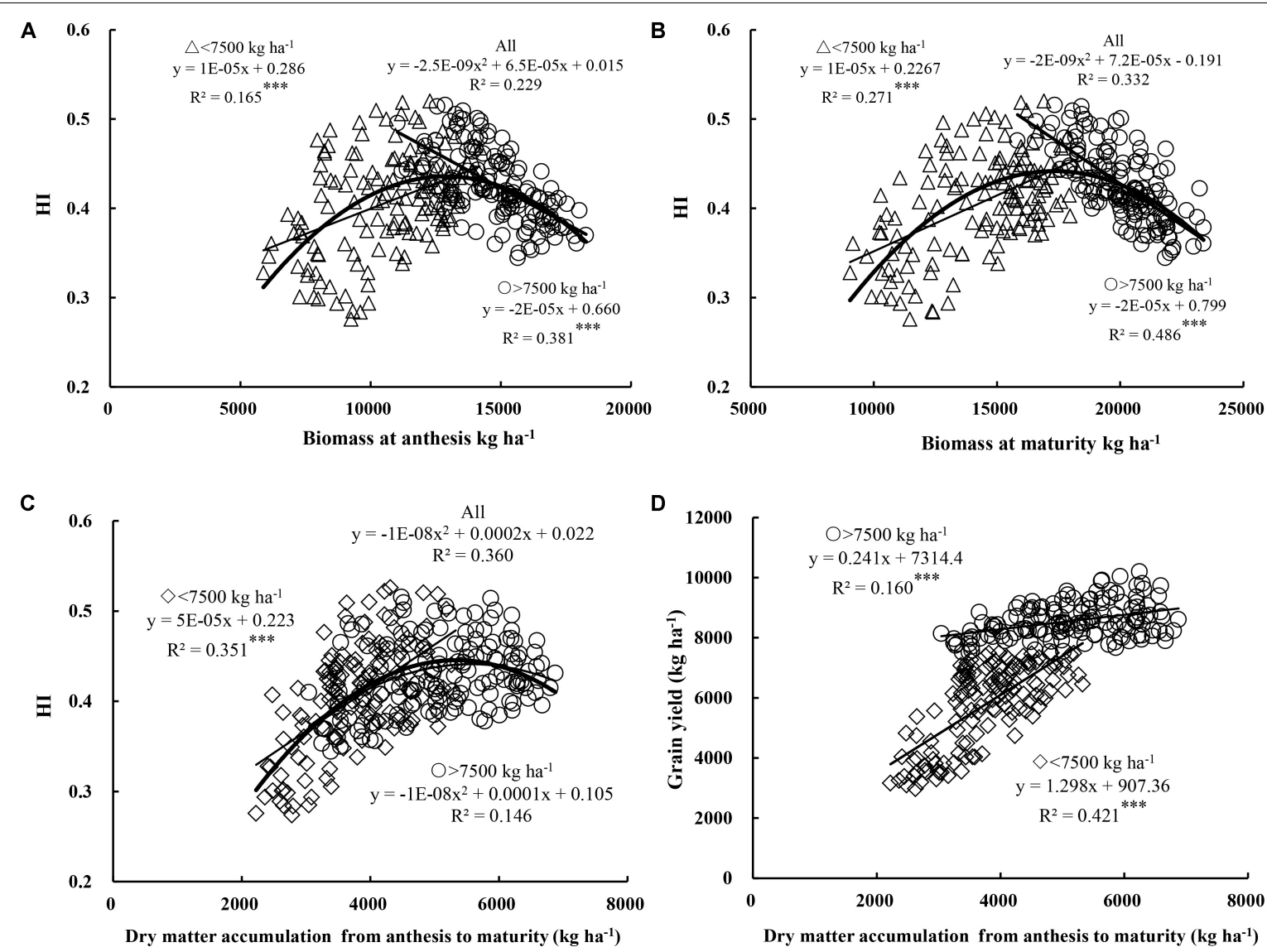

FIGURE 3 | Relationships between harvest index $(\mathrm{HI})$ and biomass at anthesis $\mathbf{( A )}$ and maturity $\mathbf{( B )}$, and relationships between DM accumulation from anthesis to maturity and $\mathrm{HI}(\mathbf{C})$ and grain yield (D), respectively. Significant at ${ }^{*} p=0.05,{ }^{* *} p=0.01$, and ${ }^{* * *} p=0.001$.

maintained a high $\mathrm{HI}$, thereby helping alleviate the negative correlation between $\mathrm{HI}$ and DM at anthesis and maturity. In addition, as shown in Figure 3D, yield exhibited a significant positive correlation with DM accumulation during anthesis to maturity under both yield levels $\left(R^{2}=0.160-0.421, P<0.001\right)$. Overall, an increase in net accumulation of DM from anthesis to maturity is therefore beneficial in terms of HI and increased yield.

\section{Effects of Leaf Area and Incident Radiation on Net DM Accumulation During Filling}

Significant positive linear relationships were observed between LAP, RIP, and net DM accumulation at $0-7,0-15$, and $0-21$ days after anthesis (Figures $4 \mathbf{A}-\mathbf{C}$ ). Moreover, the three slopes of the regression equations between net DM accumulation and LAP and RIP decreased with the advancement of grain filling, possibly due to gradual leaf senescence and decreased RI. RIP generated a higher determination coefficient compared to LAP when fitted to photosynthetic production, which is relevant in terms of light reflection, transmission, and absorption. As shown in Figure 4A, LAP also showed a significant positive linear relationship with RIP at $0-7,0-15$, and $0-21$ days after anthesis $\left(R^{2}=0.636-\right.$ $0.738, P<0.001)$, suggesting that an increase in LAP from 0 to
21 days after anthesis causes an increase in RIP. A reasonable canopy structure with optimal leaf distribution helps promote the light absorption capacity of different leaf layers, reducing light reflection and the transmission ratio. Thus, the higher the LAP and stronger the RIP, the more photosynthetic products there are to meet the needs of grain filling.

\section{Respective Relationships Between Grain Yield, RI, and LAI During Grain Filling}

Leaf vertical distribution and RI showed significant differences between different total DM levels, with RI directly affected by the spatial distribution of the leaves (Figure 5). Meanwhile, LAI gradually decreased with leaf maturation and yellowing after anthesis. As shown in Figures $\mathbf{5 A - C}$, the relationship between grain yield and LAI was determined by the canopy layer, growth stage, and total DM level, suggesting that maintaining a green leaf area for longer period and slowing down the aging process are conducive to increased yield. LAI was positively correlated with grain yield regardless of the condition of the canopy layer, growth stage, and total DM level, suggesting that high LAI is beneficial in terms of yield. When the total DM at anthesis was $<13,000 \mathrm{~kg} \mathrm{ha}^{-1}$, LAI resulted in a higher $R^{2}$ in upper compared to lower layers. Moreover, the $R^{2}$ of the upper layer showed 

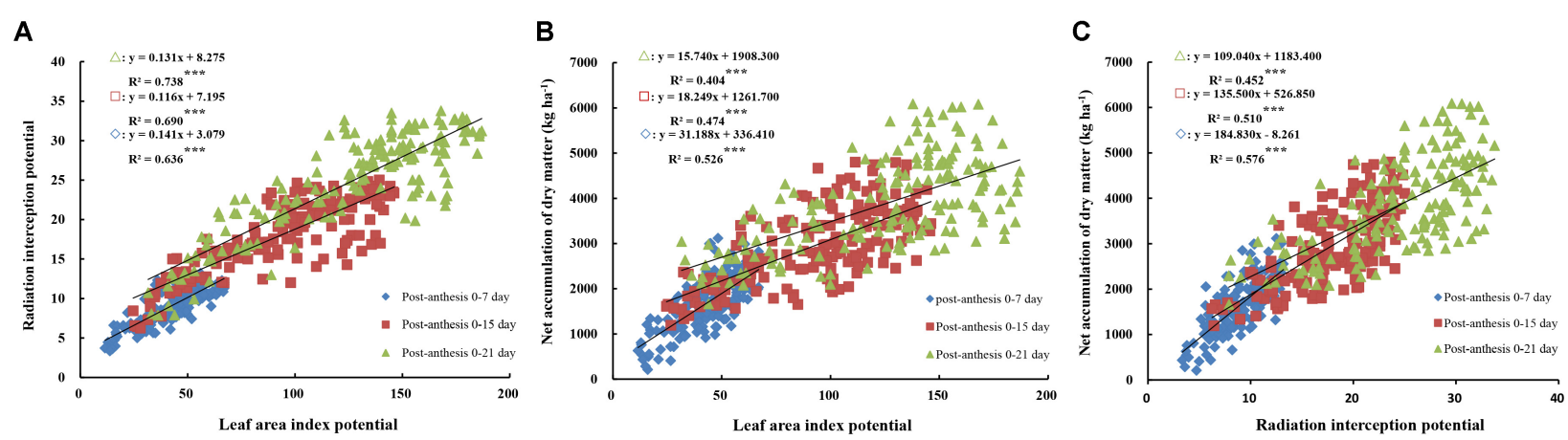

FIGURE 4 | Relationship between radiation interception (RI) potential and leaf area index (LAl) potential (A), and relationships between dry matter (DM) accumulation from anthesis to maturity, radiation interception (B) and leaf area index (C) potential. Significant at ${ }^{*} p=0.05,{ }^{* *} p=0.01$, and ${ }^{* * *} p=0.001$.

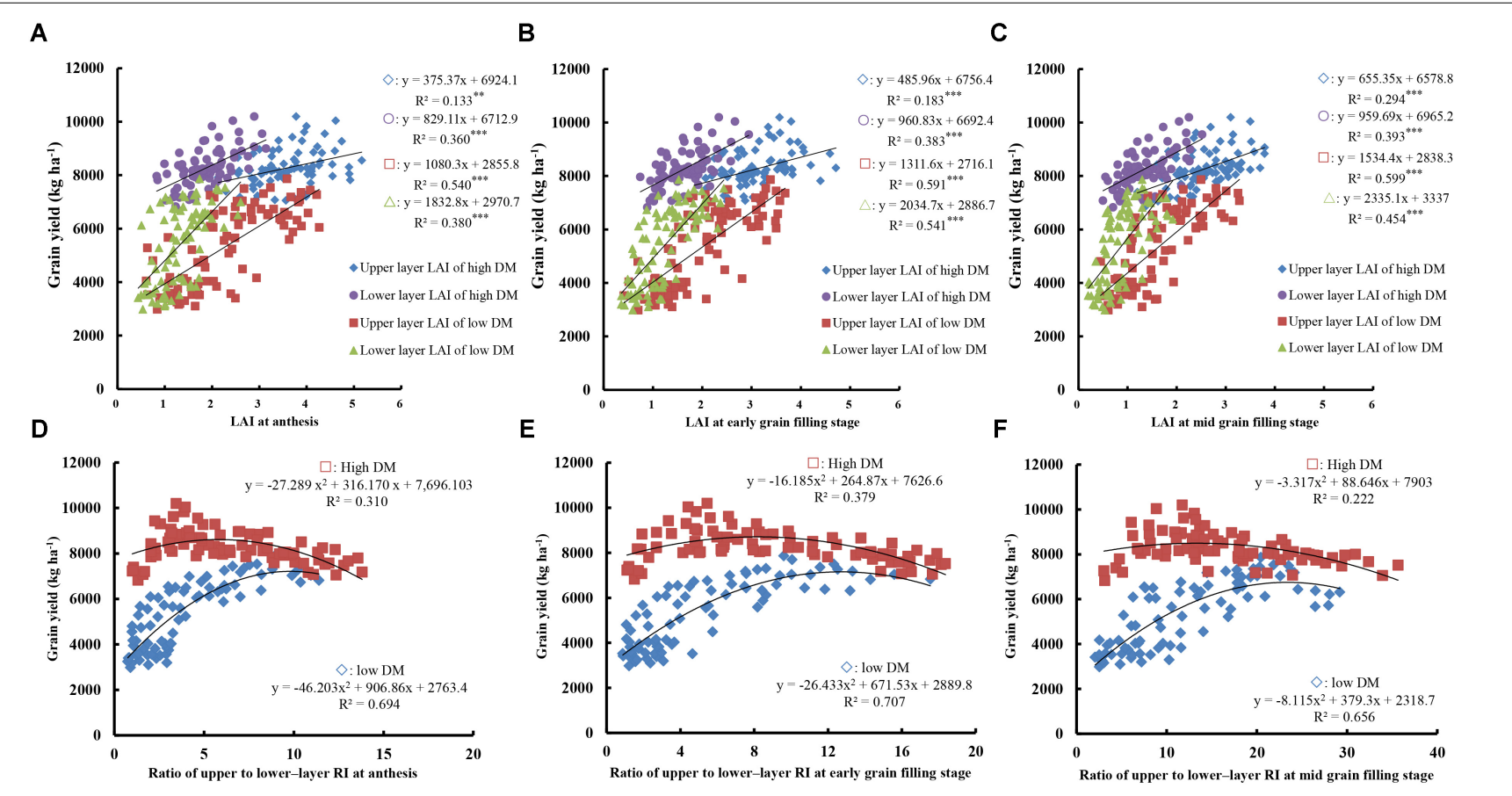

FIGURE $\mathbf{5}$ | Relationships between grain yield and the ratio of upper- to lower-layer RI, and LAl at anthesis, early, and mid-grain filling. (A-C) Relationships between yield and LAl at anthesis (A), early grain filling stage, (B) and mid grain filling stage (C). (D-F) Relationships between yield and ratio of upper- to lower-layer RI at anthesis (D), early grain filling stage, (E) and mid grain filling stage (F). High DM, DM at anthesis $>13,000 \mathrm{~kg} \mathrm{ha}^{-1}$; low DM, DM at anthesis $<13,000 \mathrm{~kg}$ ha ${ }^{-1}$. Significant at $* p=0.05,{ }^{* *} p=0.01$, and ${ }^{* * *} p=0.001$.

a more prominent trend with the advancement of grain filling $\left(R^{2}=0.540\right.$ at anthesis, 0.591 at early filling, and 0.599 at mid filling, all $P<0.001)$. However, when the total DM at anthesis was $>13,000 \mathrm{~kg} \mathrm{ha}^{-1}$, LAI demonstrated a higher $R^{2}$ in lower compared to upper layers, and the $R^{2}$ of lower layers showed a more prominent advantage with grain filling $\left(R^{2}=0.360\right.$ at anthesis, 0.383 at early filling, and 0.393 at mid filling, all $P<0.001)$.

As shown in Figures 5D-F, grain yield followed curves of a second-order equation with ratios of upper- to lower-layer RI from anthesis to mid-filling stages under both total DM levels. These findings suggest that the RI ratio has an optimal range in terms of yield. The optimum RI ratio under high DM levels was lower than that under low DM levels at anthesis, early, and mid-grain filling stages. Moreover, the optimum RI ratio gradually increased with the development of grain filling, with respective optimal ranges of 2-6,3-8, and 7-13 at anthesis, early filling, and mid filling under a high DM level and 6-10, 8-13, and 12-25 under a low DM level, respectively. These findings suggest that increases in lower-layer RI and a relatively low RI ratio are beneficial to yield when DM levels are $>13,000 \mathrm{~kg}$ $\mathrm{ha}^{-1}$. In contrast, higher upper-layer RI and a relatively high RI ratio are conducive to increased yield when DM levels are $<13,000 \mathrm{~kg} \mathrm{ha}^{-1}$. 

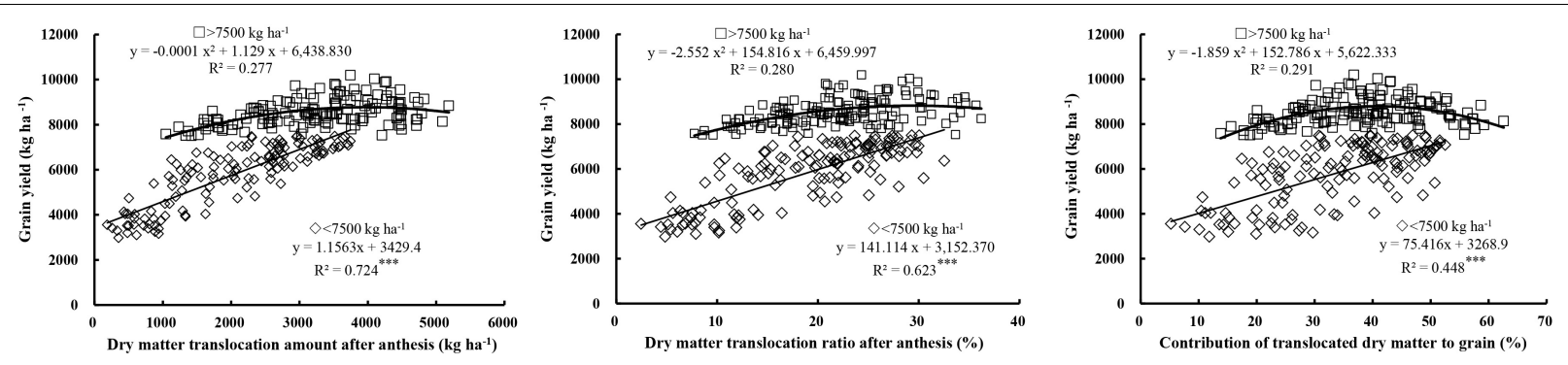

FIGURE 6 | Relationships between grain yield and the translocation amount, translocation ratio and contribution ratio of pre-anthesis dry matter (DM) to grains. Significant at ${ }^{*} p=0.05,{ }^{* *} p=0.01$, and ${ }^{* * *} p=0.001$.

\section{Contribution of DM Translocation to Yield and Growth Indictors of High Yield}

Grain yield showed a significant positive linear correlation with the translocation amount $\left(R^{2}=0.724, P<0.001\right)$, translocation ratio $\left(R^{2}=0.623, P<0.001\right)$, and contribution ratio $\left(R^{2}=0.448\right.$, $P<0.001$ ) of pre-anthesis DM under low yield levels (Figure 6), which suggests that under low yield levels improvements in the translocation amount and ratio of pre-anthesis DM are conducive to increased yield. However, in contrast, under high yield levels, the translocation amount, translocation ratio, and contribution ratio of pre-anthesis DM showed curves of a secondorder equation with yield, with optimal values for higher yield of $3000-4500 \mathrm{~kg} \mathrm{ha}^{-1}, 25-35$, and 30-50\%, respectively.

In summary, as shown in Figure 7, we propose physiological indicators of increased yield in the Huang-Huai Plain. First is an aboveground DM of $13,000-17,000 \mathrm{~kg} \mathrm{ha}^{-1}$ at anthesis, providing the basis of transportation material and thereby supporting the canopy structure. Second, as mentioned above, is the translocation of pre-anthesis DM within an optimal range of $3000-4500 \mathrm{~kg} \mathrm{ha}^{-1}$ under a translocation ratio of $25-35 \%$ and contribution ratio of $30-50 \%$. Third, is an increase in DM from anthesis to maturity of $4000-6000 \mathrm{~kg} \mathrm{ha}^{-1}$, with an RI ratio of upper to lower layers of 2-6, 3-8, and 6-13 at anthesis, early, and mid-grain filling, respectively. Lastly, is the optimal balance between aboveground DM at maturity $\left(>18,000 \mathrm{~kg} \mathrm{ha}^{-1}\right)$ and HI $(>0.42)$, which promotes yield levels of $>7500 \mathrm{~kg} \mathrm{ha}^{-1}$.

\section{DISCUSSION}

\section{Effect of Cultivation Strategy on DM Production, $\mathrm{HI}$, and Yield}

Water and nitrogen are the main limiting factors affecting crop growth (Li et al., 2009). Irrigation increases the availability of nitrogen, while nitrogen application promotes water utilization during wheat production, thereby contributing to plant growth by improving green leaf area, photosynthesis intensity, DM accumulation, and yield (Seiffert et al., 1995; Qiu et al., 2008). However, excessive irrigation and nitrogen fertilization lead to excessive vegetative growth and an increase in DM in stem and leaf organs at maturity, thereby reducing the HI (Zhao and Yu, 2006; Zhang and Yu, 2008). Previous studies suggest that irrigation at jointing plus anthesis, and a nitrogen application rate of $240-270 \mathrm{~kg} \mathrm{ha}^{-1}$ are appropriate for achieving high yield (Zhang et al., 2009, 2011). Meanwhile, Wang C.Y. et al. (2014) found that irrigation at jointing plus booting and $240 \mathrm{~kg}$ $\mathrm{N} \mathrm{ha}^{-1}$ resulted in the highest yield. In our study, DM, HI, and yield tended to increase with increasing irrigation and nitrogen application; however, a high $\mathrm{N}$ application rate of $300 \mathrm{~kg} \mathrm{~N} \mathrm{ha}^{-1}$ under W2 caused reductions in DM and yield. Cultivation management patterns involve the integration of various cultivation techniques including tillage, fertilization, irrigation, and seeding (Chen et al., 2014; Wang Y.H. et al., 2014). Chen et al. (2014) found that optimized cultivation management significantly improved the total DM, HI, and yield compared to traditional farming practices. Wang Y.C. et al. (2015) further revealed that $\mathrm{HH}$ treatment could improve the $\mathrm{DM}_{\mathrm{AM}}$ and $\mathrm{HI}$ compared to SH and FP. Our results are consistent with these findings, whereby $\mathrm{HH}, \mathrm{SH}$, and OFP treatment resulted in a higher $\mathrm{DM}_{\mathrm{AM}}$ than $\mathrm{FP}$, thereby increasing the HI.

Yield is determined by DM production, yield components, and HI, all of which show wide variation in different wheat production regions under diverse climate and soil conditions and between different cultivars (Unkovich et al., 2010; Terrile et al., 2017). Zhang et al. (2012) reported that increased yield could together with increasing HI without increase in DM, suggesting that yield could be improved via increased $\mathrm{HI}$ based on the same DM. In our study, yield, GN, DM, and HI showed wide distribution ranges, and the highest GN, DM, and HI were not always matched with the maximum yield in different locations (Tables 3-5 and Figure 2). With Yumai 49-198, a higher GN, $\mathrm{DM}_{\mathrm{AM}}$, and yield but lower HI were observed in Shangshui, compared to Kaifeng and Wenxian. Meanwhile, with Aikang 58, smaller differences were observed between Shangshui and Wenxian. On the whole, however, the two cultivars showed consistency in terms of the relationship between yield, GN, DM, and HI. That is, in both cultivars at all three locations, increases in GN formed a larger sink, promoting high DM to match the high $\mathrm{HI}$, thereby resulting in an increase in yield.

\section{Contributions of DM and $\mathrm{HI}$ to Increased Yield}

Recently, increases in wheat yield have been attributed to increases in HI (Foulkes et al., 2009; Aranjuelo et al., 2013). Moreover, since the green revolution and genetic improvements 


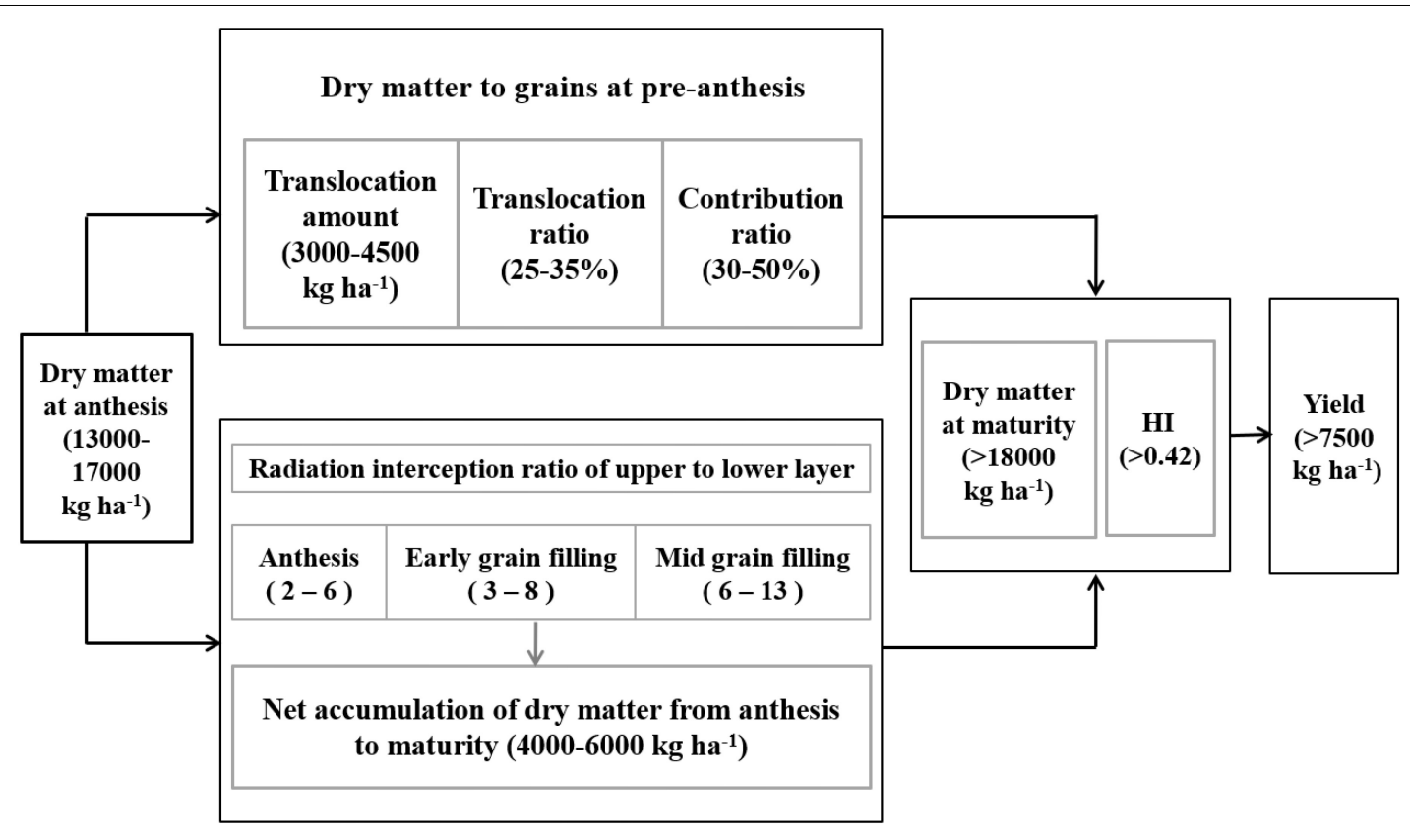

FIGURE 7 | Growth indicators of increased yield at a yield level of $>7500 \mathrm{~kg} \mathrm{ha}^{-1}$ in winter wheat.

in breeding, $\mathrm{HI}$ values have continued to reach high levels (Wiesmeier et al., 2014; Fan et al., 2017). As a result, it has been suggested that further increases in yield are now dependent on increases in total DM, providing a more solid foundation for yield formation (Parry et al., 2010; Aranjuelo et al., 2013). However, in reality, increases in both $\mathrm{HI}$ and total DM are conducive to improvements in yield within a certain range of production. Moreover, the contributions of $\mathrm{HI}$ and total DM on yield differ between ecological regions and different productivity levels (Lynch et al., 2017). Kawano (1990) reported that in rice the total DM is more important under low yielding levels, while the HI has a more significant effect under high yielding levels. Moreover, Rose et al. (2017) studied winter wheat production in Central Europe and found that while both HI and total DM are important in increasing yield, HI is more important. In our study, both total DM and HI were important under low yield levels, while HI was more important under high yield levels. These findings may be due to the long vegetative period and suitable light and temperature conditions before anthesis, which result in high DM levels under high yield levels in the Huang-Huai Plain.

Total DM can be divided into pre- and post-anthesis DM, which shows differences in determining yield by affecting GN and TGW. In Mediterranean regions, wheat yield is largely dependent on pre-anthesis DM production because of the favorable rainfall and temperature conditions, with hot dry weather after anthesis having an adverse effect on yield formation (Papakosta and Gagianas, 1991; Ercoli et al., 2008). However, in other ecoclimatic regions, post-anthesis DM production may be more important (Zhang et al., 2012). Net accumulation of post-anthesis $\mathrm{DM}$ is mainly stored in the grains and is therefore closely related to yield (Zhang et al., 2016). Our study confirmed the importance of post-anthesis DM on increasing yield under high yield levels, while pre-anthesis DM was found to play a more important role in yield under low yield levels.

\section{Effect of DM Production During Filling on $\mathrm{HI}$}

HI is significantly affected by various morphological and physiological traits including plant height and DM partitioning into the spikes (Sayre et al., 1997; Zhang et al., 2012). However, with breeding of dwarf genes into modern wheat and plant height reaching an optimal level, the effect on HI has become weaker (Zhang et al., 2012). Increased partitioning of photosynthates to grains could improve HI via adequate reductions in the structure of the stem, rachis, glume, and palea (Palta et al., 1994; Foulkes et al., 2011). Thus, increases in HI could improve yield under the same DM. In this study, HI tended to show a parabolic relationship with total DM. Specifically, HI was positively correlated with total DM under low yield levels, but negatively under high yield levels. These findings suggest that higher yield is achieved via a balance between total DM and HI, while excessive DM production breaks this balance, subsequently reducing HI and decreasing yield. Further studies suggest that improved post-anthesis remobilization of water-soluble carbohydrates in the stem, leaf, and sheath to the grains also increase HI (Yang et al., 2000; Foulkes et al., 2007). Net accumulation of DM during filling also plays a very important role in ensuring a high sink (Bustos et al., 2013; Zhang et al., 2016). A larger sink provides a sufficient structural foundation for storing assimilates, and therefore, improving HI (Zhang et al., 2012). Our results are consistent with this, with a significant positive correlation between GN and HI, which requires more photosynthates during filling to meet the demands of the sink. Compared to total DM, net accumulation of DM during filling was important in terms 
of increased HI under low yield levels, but significantly alleviated the negative correlation with HI under high yield levels, thereby contributing to reaching a new balance between high $\mathrm{HI}$ and total $\mathrm{DM}$ in terms of increased yield. Overall, therefore, maintaining high net accumulation of DM during filling is beneficial in terms of achieving high HI under both high and low yield levels.

\section{Canopy Architecture Characteristics of RI and LAI During Grain Filling}

Effective canopy architecture provides a suitable leaf layout and space structure for adaptation to different light radiation environments (Zhang et al., 2003; Dong et al., 2015). Optimal canopy architecture delays leaf senescence by adjusting the temperature and humidity to allow interception of more light radiation. Previous research suggests that interception of light radiation is determined by the leaf area and plant type (Ceotto et al., 2013; Du et al., 2015). In this study, we examined LAP and corresponding RIP, revealing an increase in RIP with increasing LAP. In line with this, some studies suggest that DM production relies on the ability of the canopy to intercept light radiation via the function of green leaves and conversion of solar energy into DM (Miralles and Slafer, 1997; Reynolds et al., 2005; Schierenbeck et al., 2016). In our study, both LAP and RIP showed close correlations with DM production, where a higher LAP and RIP after anthesis contributed to increases in net DM accumulation after anthesis. A longer green leaf duration and higher radiation interception after anthesis are therefore particularly important in terms of DM and yield.

Previous studies also suggest that LAI accurately reflects the radiation interception capacity and canopy architecture (Plenet et al., 2000; Li et al., 2010). An optimal crop canopy is able to effectively intercept and use solar radiation, thereby promoting photosynthesis and DM production (Li et al., 2010). The vertical distribution of leaves therefore has a direct effect on the interception and distribution of radiation within the canopy. Li et al. (2010) reported that the leaf area density within the upper and middle layers of the canopy increases with plant growth, while that of the lower layer decreases. In our study, upper- and lower-layer LAI under different total DM levels was positively correlated with yield. Compared to low yield levels, a higher lower-layer leaf area was more important in terms of yield under high yield levels. This was possibly due to the effect of maintaining more lower-layer leaves and delaying leaf senescence to intercept more radiation, with more nutriment being produced in lower layers and preferentially transferred to the root organs. Canopy architecture and leaf area both have effects on radiation interception (Du et al., 2015). In this study, the relationship between yield and the ratio of upper- to lower-layer RI followed curves of a second-order equation at different stages. The optimal ratios of upper- to lower-layer RI at anthesis, early, and midfilling were, respectively, within the ranges of 2-6, 3-8, and 6-13 under high total DM at anthesis of $>13,000 \mathrm{~kg} \mathrm{ha}^{-1}$, and 6-10, $8-13$, and 12-25, respectively, under low total DM at anthesis of $<13,000 \mathrm{~kg} \mathrm{ha}^{-1}$. Values above and below these optimal ratio ranges reduce radiation interception, leading to less effective use of radiation. In addition, under high total DM at anthesis, the optimal ratio was lower than that under low total DM, suggesting that a higher RI ratio in lower layers is beneficial to yield due to increased interception and use of radiation in lower layers, and therefore, resulting in increased production of photosynthetic assimilates.

\section{Characteristics of DM Production and Translocation}

In general, grain yield is the result of DM assimilation and translocation of mobilized nutrients from vegetative organs (Sadras and Lawson, 2011). Previous studies suggest that increased allocation of assimilates to reproductive organs helps improve the sink and yield potential (Richards, 2000; Zhang et al., 2008). Fischer (1981) suggested that high DM production at post-anthesis tends to promote storage of assimilates in grains compared to stems and leaves, thereby increasing HI and yield. In our study, under low yield levels, accelerated translocation of assimilates from pre-anthesis vegetative organs to grains and a higher contribution ratio of translocation to grains helped increase yield. Under high yield levels, the relationship between the translocation and contribution of pre-anthesis assimilates and yield followed a second-order curve, with an optimal translocation amount of $3000-4500 \mathrm{~kg} \mathrm{ha}^{-1}$, translocation ratio of $25-35 \%$, and contribution ratio of $30-50 \%$. These findings suggest that maintaining the balance between DM production at pre- and post-anthesis, to ensure higher post-anthesis DM productivity, contributes to increases in $\mathrm{HI}$, and therefore, higher yield.

The physiological indicators of increased yield differ between different regions and productivity levels (Papakosta and Gagianas, 1991; Rose et al., 2017). In the Mediterranean regions, yield is largely dependent on the translocation of pre-anthesis assimilates, with total DM at maturity generally $<15,000 \mathrm{~kg} \mathrm{ha}^{-1}$ (Ercoli et al., 2008). Meanwhile, in the high rainfall zones of southern Australia, yield is correlated with total post-anthesis net DM accumulation and translocation of pre-anthesis assimilates, with the total DM at maturity generally being $<18,000 \mathrm{~kg} \mathrm{ha}^{-1}$ (Zhang et al., 2012). In this study, net DM accumulation ranged between 4000 and $6000 \mathrm{~kg} \mathrm{ha}^{-1}$ during filling, resulting in a HI value of $>0.42$ and $\mathrm{DM}$ at maturity value of $>18,000 \mathrm{~kg}$ $\mathrm{ha}^{-1}$, thereby reaching higher yield. This study was conducted in multiple sites across several years, providing an important basis for future breeding programs and the production of wheat in the Huang-Huai Plain. Further studies are now required to determine the appropriate field management aimed at promoting net accumulation of DM during filling.

\section{CONCLUSION}

In the Huang-Huai Plain, increased yield under low yield levels was attributed to increases in both total DM and HI, while under high yield levels increasing yield was largely dependent on further improvement in HI. Under high yield levels, high net DM accumulation during filling reached $4000-6000 \mathrm{~kg} \mathrm{ha}^{-1}$ via increases in LAP and RIP, thereby resulting in a high HI. The ratios of upper- to lower-layer RI showed curves of a secondorder equation with yield after anthesis. Meanwhile, under high 
total DM levels, higher lower-layer LAI allowed interception of more radiation, with a decrease in the interception ratio of upper to lower layers, thereby increasing post-anthesis DM production and yield. Moreover, for the contribution of pre-anthesis DM to grains, accelerating DM mobilization from vegetative organs to grains was beneficial to yield. In this region, the following growth indicators were subsequently proposed to achieve higher yield: DM at anthesis of 13,000-17,000 $\mathrm{kg} \mathrm{ha}^{-1}$, net DM accumulation after anthesis of $4000-6000 \mathrm{~kg} \mathrm{ha}^{-1}$, DM at maturity of $>18,000 \mathrm{~kg} \mathrm{ha}^{-1}$, and $\mathrm{HI}$ of $>0.42$. Under the climatic conditions of the three experimental locations, cultivars Yumai 49-198 and Aikang 58 showed the same pathway to increase yield, i.e., an increase in GN to form a larger sink and high net accumulation of DM during filling increases HI, thereby contributing to increases in yield. Hence, $\mathrm{N}$ applied as basal fertilizer and irrigation after sowing should be appropriately reduced to promote root growth downward and breed strong seedling; $\mathrm{N}$ topdressing (50-60\%) and irrigation should be applied in jointing for optimizing canopy structure and improving sink. Meanwhile, supplementary irrigation at anthesis contributes to improving plant activity, delaying leaf senescence, and producing more net DM, and therefore, increasing $\mathrm{HI}$ and improving yield.

\section{REFERENCES}

Aranjuelo, I., Sanzsaez, A., Jauregui, I., Irigoyen, J. J., Araus, J. L., Sanchezdiaz, M., et al. (2013). Harvest index, a parameter conditioning responsiveness of wheat plants to elevated CO2. J. Exp. Bot. 64, 1879-1892. doi: 10.1093/jxb/ert081

Austin, R. B. (1980). "Physiological limitations to cereals yields and ways of reducing them by breeding," in Opportunities for Increasing Crop Yields, eds R. G. Hurd, P. V. Biscoe, and C. Dennis (London: Association of Applied Biology/Pitman), 3-9.

Bustos, D. V., Hasan, A. K., Reynolds, M. P., and Calderini, D. F. (2013). Combining high grain number and weight through a DH-population to improve grain yield potential of wheat in high-yielding environments. Field Crops Res. 145, 106-115. doi: 10.1016/j.fcr.2013.01.015

Ceotto, E., Candilo, M. D., Castelli, F., Badeck, F. W., Rizza, F., Soave, C., et al. (2013). Comparing solar radiation interception and use efficiency for the energy crops giant reed (Arundo donax L.) and sweet sorghum (Sorghum bicolor L. Moench). Field Crops Res. 149, 159-166. doi: 10.1016/j.fcr.2013.05.002

Chen, X. P., Cui, Z. L., Fan, M. S., Vitousek, P., Zhao, M., and Ma, W. Q. (2014). Producing more grain with lower environmental costs. Nature 514, 486-489. doi: 10.1038/nature13609

Dong, C., Shao, L. Z., Liu, G. H., Wang, M. J., Liu, H., Xie, B. Z., et al. (2015). Photosynthetic characteristics, antioxidant capacity and biomass yield of wheat exposed to intermittent light irradiation with millisecond-scale periods. J. Plant Physiol. 184, 28-36. doi: 10.1016/j.jplph.2015.06.012

Du, X. B., Chen, B. L., Shen, T. Y., Zhang, Y. X., and Zhou, Z. G. (2015). Effect of cropping system on radiation use efficiency in double-cropped wheat-cotton. Field Crops Res. 170, 21-31. doi: 10.1016/j.fcr.2014.09.013

Ercoli, L., Lulli, L., Mariotti, M., Masoni, A., and Arduini, I. (2008). Post-anthesis dry matter and nitrogen dynamics in durum wheat as affected by nitrogen supply and soil water availability. Eur. J. Agron. 28, 138-147. doi: 10.1016/j.eja. 2007.06.002

Evans, L. T., and Fischer, R. A. (1999). Yield potential: its definition, measurement, and significance. Crop Sci. 39, 1544-1551. doi: 10.2135/cropsci1999.3961544x

Fan, J., Mcconkey, B., Janzen, H., Townley-Smith, L., and Wang, H. (2017). Harvest index-yield relationship for estimating crop residue in cold continental climates. Field Crops Res. 204, 153-157. doi: 10.1016/j.fcr.2017.01.014

Fischer, R. A. (1981). Optimizing the use of water and nitrogen through breeding of crops. Plant Soil 58, 249-278. doi: 10.1007/BF02180056

\section{AUTHOR CONTRIBUTIONS}

WF, YuZ, and TG designed the experiments. JD, YW, YiZ, and XR carried out the experiments. JD and WF analyzed the experimental results and wrote the manuscript. YS and LH assisted in writing and editing the manuscript.

\section{FUNDING}

This work was supported by grants from the Special Fund for the thirteenth five-year plan of the National Key Research Project of China (Grant No. 2016YFD0300604), Agro-scientific Research in the Public Interest (Grant No. 201203096), the National Natural Science Foundation of China (Grant Nos. 31671624 and 31571607), the Program of Science and Technology Innovation Talents in Universities of Henan Province, China (Grant No. 17HASTIT036), and the National Agriculture Technology Research System of China (Grant No. CARS-0301-22).

Fischer, R. A. (1985). Number of kernels in wheat crops and the influence of solar radiation and temperature. J. Agric. Sci. 105, 447-461. doi: 10.1017/ S0021859600056495

Foulkes, M., Sylvester-Bradley, R., Weightman, R., and Snape, J. (2007). Identifying physiological traits associated with improved drought resistance in winter wheat. Field Crops Res. 103, 11-24. doi: 10.1016/j.fcr.2007.04.007

Foulkes, M. J., Reynolds, M. P., and Sylvester-Bradley, R. (2009). "Genetic improvement of grain crops: yield potential," in Crop Physiology: Applications for Genetic Improvement and Agronomy, eds V. O. Sadras and D. F. Calderini (Burlinggton, NJ: Elsevier), 355-385. doi: 10.1016/B978-0-12-374431-9. 00015-3

Foulkes, M. J., Slafer, G. A., Davies, W. J., Berry, P. M., Sylvester-Bradley, R., Martre, P., et al. (2011). Raising yield potential of wheat. III. Optimizing partitioning to grain while maintaining lodging resistance. J. Exp. Bot. 62, 469-486. doi: 10.1093/jxb/erq300

Kawano, K. (1990). Harvest index and evolution of major food crop cultivars in the tropics. Euphytica 46, 195-202. doi: 10.1007/BF00027218

Li, S. X., Wang, Z. H., Malhi, S., Li, S. Q., Gao, Y. J., and Tian, X. H. (2009). Nutrient and water management effects on crop production, and nutrient and water use efficiency in dryland areas of China. Adv. Agron. 102, 223-265. doi: 10.1016/S0065-2113(09)01007-4

Li, Y.-d., Tang, L., Zhang, Y.-p., Zhu, X.-c, Cao, W.-X., and Zhu, Y. (2010). Relationship of PAR interception of canopy to leaf area and yield in rice. Sci. Agric. Sin. 43, 3296-3305. doi: 10.3864/j.issn.0578-1752.2010.16.004

Lynch, J. P., Doyle, D., McAuley, S., McHardy, F., Danneels, Q., Black, L. C., et al. (2017). The impact of variation in grain number and individual grain weight on winter wheat yield in the high yield potential environment of Ireland. Eur. J. Agron. 87, 40-49. doi: 10.1016/j.eja.2017.05.001

Merchukovnat, L., Fahima, T., Krugman, T., and Saranga, Y. (2016). Ancestral QTL alleles from wild emmer wheat improve grain yield, biomass and photosynthesis across environments in modern wheat. Plant Sci. 251, 23-34. doi: 10.1016/j. plantsci.2016.05.003

Miralles, D. J., and Slafer, G. A. (1997). Radiation interception and radiation use efficiency of near-isogenic wheat lines with different height. Euphytica 97, 201-208. doi: 10.1023/A:1003061706059

Nass, H. G. (1980). Harvest index as a selection criterion for grain yield in two spring wheat crosses grown at two population densities. Can. J. Plant Sci. 60, 1141-1146. doi: 10.4141/cjps80-166 
Palta, J. A., Kobata, T., Turner, N. C., and Fillery, I. R. (1994). Remobilization of carbon and nitrogen in wheat as influenced by postanthesis water deficits. Crop Sci. 34, 118-124. doi: 10.2135/cropsci1994.0011183X003400010021x

Papakosta, D. K., and Gagianas, A. A. (1991). Nitrogen and dry matter accumulation, remobilization, and losses for Mediterranean wheat during grain filling. Agron. J. 83, 864-870. doi: 10.2134/agronj1991.00021962008300050018x

Parry, M. A. J., and Hawkesford, M. J. (2010). Food security: increasing yield and improving resource use efficiency. Proc. Nutr. Soc. 69, 592-600. doi: 10.1017/ S0029665110003836

Parry, M. A. J., Reynolds, M. P., Salvucci, M. E., Raines, C. A., Andralojc, P. J., Zhu, X., et al. (2010). Raising yield potential of wheat. II. Increasing photosynthetic capacity and efficiency. J. Exp. Bot. 62, 453-467. doi: 10.1093/ jxb/erq304

Plenet, D., Etchebest, S., Mollier, A., and Pellerin, S. (2000). Growth analysis of maize field crops under phosphorus deficiency. Plant Soil 223, 119-132. doi: 10.1023/A:1004877111238

Qin, X., Zhang, F., Liu, C., Yu, H., Cao, B., Tian, S., et al. (2015). Wheat yield improvements in China: Past trends and future directions. Field Crops Res. 177, 117-124. doi: 10.1016/j.fcr.2015.03.013

Qin, X. L., Weiner, J., Qi, L., Xiong, Y. C., and Li, F. M. (2013). Allometric analysis of the effects of density on reproductive allocation and harvest index in 6 varieties of wheat (Triticum). Field Crops Res. 144, 162-166. doi: 10.1016/j.fcr. 2012.12.011

Qiu, G. Y., Wang, L. M., He, X. H., Zhang, X. Y., Chen, S. Y., and Chen, J. (2008). Water use efficiency and evapotranspiration of winter wheat and its response to irrigation regime in the north China plain. Agric. For. Meteor. 148, 1848-1859. doi: 10.1016/j.agrformet.2008.06.010

Reynolds, M., Pellegrineschi, A., and Skovmand, B. (2005). Sink-limitation to yield and biomass: a summary of some investigations in spring wheat. Ann. Appl. Biol. 146, 39-49. doi: 10.1111/j.1744-7348.2005.03100.x

Richards, R. A. (2000). Selectable traits to increase crop photosynthesis and yield of grain crops. J. Exp. Bot. 51, 447-458. doi: 10.1093/jexbot/51.suppl_1.447

Rose, T., Nagler, S., and Kage, H. (2017). Yield formation of Central-European winter wheat cultivars on a large scale perspective. Eur. J. Agron. 86, 93-102. doi: 10.1016/j.eja.2017.03.003

Ru, Z. G., Feng, S. W., and Li, G. (2015). High-yield potential and effective ways of wheat in Yellow \& Huai River Valley facultative winter wheat region. Sci. Agric. Sin. 48, 3388-3393. doi: 10.3864/j.issn.0578-1752.2015.17.006

Sadras, V. O., and Lawson, C. (2011). Genetic gain in yield and associated changes in phenotype, trait plasticity and competitive ability of South Australian wheat varieties released between 1958 and 2007. Crop Pasture Sci. 62, 533-549. doi: 10.1071/CP11060

Sayre, K. D., Rajaram, S., and Fischer, R. A. (1997). Yield potential progress in short bread wheats in Northwest Mexico. Crop Sci. 37, 36-42. doi: 10.2135/ cropsci1997.0011183X003700010006x

Schierenbeck, M., Fleitas, M. C., Miralles, D. J., and Simón, M. R. (2016). Does radiation interception or radiation use efficiency limit the growth of wheat inoculated with tan spot or leaf rust? Field Crops Res. 199, 65-76. doi: 10.1016/ j.fcr.2016.09.017

Seiffert, S., Kaselowsky, J., Jungk, A., and Claassen, N. (1995). Observed and calculated potassium uptake by maize as affected by soil water content and bulk density. Agron. J. 87, 1070-1077. doi: 10.2134/agronj1995. $00021962008700060007 \mathrm{x}$

Slafer, G. A., Satore, E. A., and Andrade, F. H. (1994). "Increases in grain yield in bread wheat from breeding and associated physiological changes," in Genetic Improvement of Field Crops, ed. G. A. Slafer (New York, NY: Marcel Dekker), $1-68$.

Slafer, G. A., Savin, R., and Sadras, V. O. (2014). Coarse and fine regulation of wheat yield components in response to genotype and environment. Field Crops Res. 157, 71-83. doi: 10.1016/j.fcr.2013.12.004

Terrile, I. I., Miralles, D. J., and González, F. G. (2017). Fruiting efficiency in wheat (Triticum aestivum $\mathrm{L}$ ): Trait response to different growing conditions and its relation to spike dry weight at anthesis and grain weight at harvest. Field Crops Res. 201, 86-96. doi: 10.1016/j.fcr.2016.09.026

Unkovich, M., Baldock, J., and Forbes, M. (2010). "Chapter 5 - variability in harvest index of grain crops and potential significance for carbon accounting: examples from Australian agriculture," in Advances in Agronomy, ed. L. S. Donald (Cambridge, MA: Academic Press), 173-219. doi: 10.1016/S00652113(10)05005-4
Wang, C. Y., Liu, W. X., Li, Q. X., Ma, D. Y., Lu, H. F., and Feng, W. (2014). Effects of different irrigation and nitrogen regimes on root growth and its correlation with above-ground plant parts in high-yielding wheat under field conditions. Field Crops Res. 2014, 138-149. doi: 10.1016/j.fcr.2014.04.011

Wang, H. G., Li, D. X., Li, Y. M., and Li, R. Q. (2015). Yield components and population and individual characteristics of growth and development of winter wheat over $10000 \mathrm{~kg}$ ha-1 in Hebei province. Sci. Agric. Sin. 14, 2718-2729. doi: 10.3864/j.issn.0578-1752.2015.14.004

Wang, Y. C., Li, C. X., Dai, X. L., Zhou, X. Y., Zhang, Y., and Li, H. Y. (2015). Effects of cultivation patterns on the radiation use and grain yield of winter wheat. Chin. J. Appl. Ecol. 26, 2707-2713. doi: 10.13287/j.1001-9332.20150630.013

Wang, Y. H., Hu, W. L., Zhang, X. L., Li, L. X., Kang, G. Z., and Feng, W. (2014). Effects of cultivation patterns on winter wheat root growth parameters and grain yield. Field Crops Res. 156, 208-218. doi: 10.1016/j.fcr.2013.11.017

Wei, Y. M., Zhang, P., Guan, E. Q., Zhang, G. Q., Zhang, Y. Q., and Song, Z. M. (2013). Advances in study of quality property improvement of winter wheat in China. Sci. Agric. Sin. 20, 4189-4196. doi: 10.3864/j.issn.0578-1752.2013.20.002

Wiesmeier, M., Hübner, R., Dechow, R., Maier, H., Spörlein, P., Geuß, U., et al. (2014). Estimation of past and recent carbon input by crops into agricultural soils of southeast Germany. Eur. J. Agron. 61, 10-23. doi: 10.1016/j.eja.2014. 08.001

Yang, J. C., Zhang, J. H., Huang, Z. L., Zhu, Q. S., and Wang, L. (2000). Remobilization of carbon reserves is improved by controlled soil-drying during grain filling of wheat. Crop Sci. 40, 1645-1655. doi: 10.2135/cropsci2000. $4061645 \mathrm{x}$

Yu, Q. Y., Wu, W. B., You, L. Z., Zhu, T. J., Vliet, J. V., Verburg, P. H., et al. (2017). Assessing the harvested area gap in China. Agric. Syst. 153, 212-220. doi: 10.1016/j.agsy.2017.02.003

Zhang, F. Q., Wang, X. Y., Yu, Z. W., Wang, X. Z., and Bai, H. L. (2009). Characteristics of accumulation and distribution of Nitrogen and dry Matter in wheat at yield level of ten thousand kilograms per hectare. Acta Agron. Sin. 35, 1086-1096. doi: 10.3724/SP.J.1006.2009.01086

Zhang, H. P., Turner, N. C., and Poole, M. L. (2012). Increasing the harvest index of wheat in the high rainfall zones of southern Australia. Field Crops Res. 129, 111-123. doi: 10.1016/j.fcr.2012.02.002

Zhang, S. R., Ma, K. P., and Chen, L. Z. (2003). Response of photosynthetic plasticity of Paeonia suffruticosa to changed light environments. Environ. Exp. Bot. 49, 121-133. doi: 10.1016/S0098-8472(02)00063-1

Zhang, X. Y., Chen, S. Y., Sun, H. Y., Pei, D., and Wang, Y. M. (2008). Dry matter, harvest index, grain yield and water use efficiency as affected by water supply in winter wheat. Irrigation Sci. 27, 1-10. doi: 10.1007/s00271-0080131-2

Zhang, Y., Xu, W. G., Wang, H. W., Dong, H. B., Qi, X. L., Zhao, M. Z., et al. (2016). Progress in genetic improvement of grain yield and related physiological traits of Chinese wheat in Henan Province. Field Crops Res. 199, 117-128. doi: 10.1016/j.fcr.2016.09.022

Zhang, Y. L., and Yu, Z. W. (2008). Effects of irrigation amount on nitrogen uptake, distribution, use, and grain yield and quality in wheat. Acta Agron. Sin. 34, 870-878. doi: 10.3724/SP.J.1006.2008.00870

Zhang, Y. P., Zhang, Y. H., Wang, Z. M., and Wang, Z. J. (2011). Characteristics of canopy structure and contributions of non-leaf organs to yield in winter wheat under different irrigated conditions. Field Crops Res. 123, 187-195. doi: 10.1016/j.fcr.2011.04.014

Zhao, J. Y., and Yu, Z. W. (2006). Effects of nitrogen fertilizer rate on uptake, distribution and utilization of nitrogen in winter wheat under high yielding cultivated condition. Acta Agron. Sin. 32, 484-490. doi: 10.3321/j.issn:04963490.2006.04.003

Conflict of Interest Statement: The authors declare that the research was conducted in the absence of any commercial or financial relationships that could be construed as a potential conflict of interest.

Copyright (c) 2018 Duan, Wu, Zhou, Ren, Shao, Feng, Zhu, He and Guo. This is an open-access article distributed under the terms of the Creative Commons Attribution License (CC BY). The use, distribution or reproduction in other forums is permitted, provided the original author(s) and the copyright owner(s) are credited and that the original publication in this journal is cited, in accordance with accepted academic practice. No use, distribution or reproduction is permitted which does not comply with these terms. 